\title{
ELECTRIC FIELD MEASUREMENTS AND THE IDENTIFICATION OF CURRENTS . CAUSING MAGNETIC DISTURBANCES IN THE POLAR CAP
}

\author{
J. P. HEPPNER \\ J. D. STOLARIK \\ E. M. WESCOTT
}

OCTOBER 1970

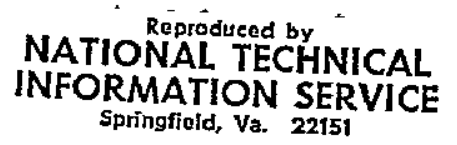

GODDARD SPACE FLIGHT CENTER GREENBELT, MARYLAND
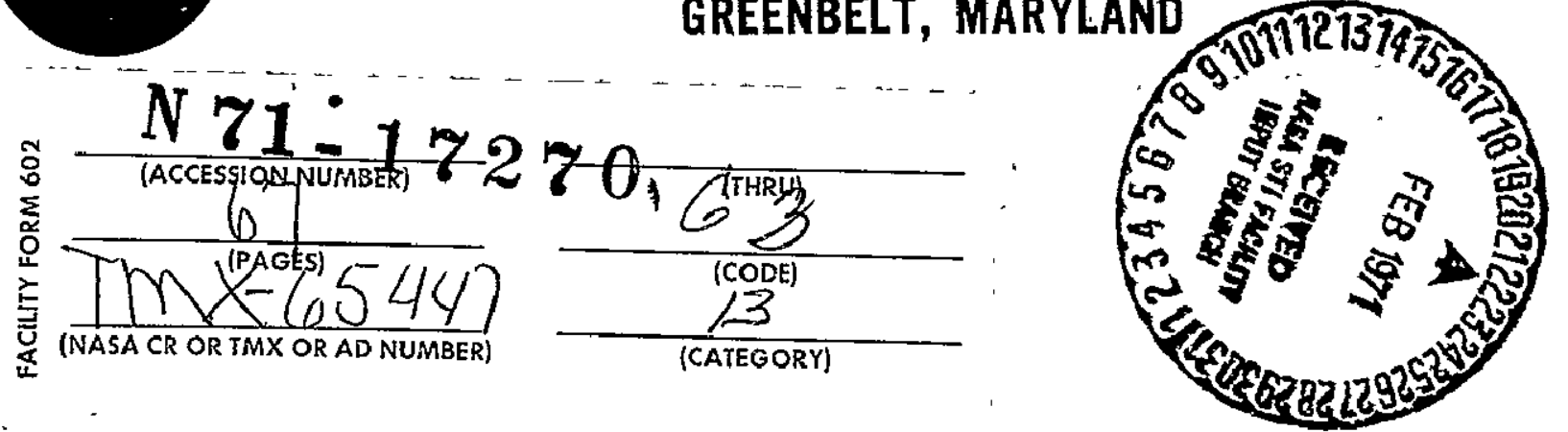
Electric Field Measurements and the Identification of Currents Causing Magnetic Disturbances in the Polar Cap

J. P. Heppner

J. D. Stolarik

E. M. Wescott*

- NASA Goddard Space Flight Center

Greenbelt, Maryland

October 1970

*Now at the Geophysical Institute, University of Alaska, College, Alaska 
Abstract

Twelve $\mathrm{Ba}^{+}$clouds were released at invariant latitudes $76^{\circ}$ to $78^{\circ}$ from three rockets luanched from Cape Parry, N.W.T., Canada for the study of polar cap electric fields and their relationship to polar cap magnetic field disturbances. All flights occurred under conditions typical for disturbances with Kp near 3. E was typically between 20 and 40 volts/km, directed roughly from dawn toward dusk, and was more uniform in space. and time than $\underline{\text { fields }}$ observed in the auroral belt. In one flight the small scale variability became large as aurora advanced northward toward the clouds. The most important aspect of the measurements was the finding of a large angular difference between the direction of $\mathrm{E}$ and $\underset{\sim}{ }$, the horizontal polar cap magnetic disturbance. This meant that $\Delta H$ could not be caused by ionospheric Hall currents in the form of a sheet current across the polar cap; also the angular difference was of the opposite sign to that expected if other elements of the conductivity tensor were important. Various factors led to the conclusion that $\Delta H$ was caused almost entirely by a source other than overhead ionospheric currents. This conclusion, enforced by a review of nighttime electron density data between 100 and $130 \mathrm{~km}$, has the consequence that continuity for Hall current auroral electrojets cannot be achieved by way of the polar cap and middle latitude ionospheres as assumed in the past. A mutual solution for both the $\Delta \mathrm{H}$ problem and the continuity problem was found in terms of a new model for continuity of the Hall current auroral electrojets. Continuity by way of field aligned currents is primarily a consequence of $(\operatorname{grad} N) / N$ being greater than $(\operatorname{grad} \underset{\sim}{\mathbb{E}}) / \underline{\mathrm{E}}$. The large scale properties of grad N/grad E appear to be compatible with the net $\therefore$. distribution of field aligned currents required to explain both the polar cap $\Delta \mathrm{H}$ and the simultaneous magnetic disturbance observed between roughly $50^{\circ}$ 
magnetic latitude and the low latitude edge of the auroral belt. The net field aligned currents are equivalent to having two sheet currents flowing "out of" and "into" auroral belt ionosphere, respectively, in the magnetic Iocal time sectors $20-24^{h}$ and $8-12^{h}$. Cause and effect between field aligned currents and precipitating particles is implied in that the distribution of grad $\mathrm{N}$ at $100-130 \mathrm{~km}$ depends on the distribution of precipitating (i.e., ionizing) particles. 
Introduction

Observations of $\mathrm{Ba}^{+}$cloud motions within the belt of auroral electrojets and near its southern edge in the northern hemisphere [Föppl et a.1., 1968; Wescott et al., 1969; Haerendel et al., 1969; Wescott et al., 1970, Haerendel and lüst, 1970; and more recent unpublished observations] have been effective in revealing the characteristics of electric fields in auroral regions. Through analyses of the simultaneous magnetic disturbances at the earth's surface it has been repeatedly demonstrated that northward electric fields accompany $+\Delta \mathrm{H}$ (positive bay) disturbances in the evening sector and that southward electric fields accompany $-\Delta \mathrm{H}$ (negative bay) disturbances in the midnight to mid-morning sector. This general result was correctly anticipated in advance of experiment from models which attribute the electrojets to Hall currents. In addition to demonstrating the dominant role of Hall currents the release experiments in auroral regions have provided extensive new information of a more detailed nature relevant to undexstanding ionospheremagnetosphere interactions.

In contrast with the expectation (and subsequent verification, noted above) that $\mathrm{Hall}$ currents were primarily responsible for magnetic disturbances in auroral regions, Heppner [1969] expressed doubt that this would also be the case in the polar cap. The principal reservation came from noting, as previously noted by others [e.g. Cole, 1963], that statistics, respectively, on the alignment of polar cap auroras and the direction of the horizontal magnetic disturbance did not indicate that these directions were mutually perpendicular as would be expected if the aurora frequently aligned along convection paths and the magnetic disturbance was caused by a Hall current. This doubt, coupled with the importance of 
establishing the validity of the usual practice [e.g., Axford and Hines, 1961, Taylor and Hones, 1965] of using the properties of polar cap magnetic disturbances to determine the electric field throughout the geomagnetic tail, suggested an urgent need for polar cap measurements. The Cape Parry ion cloud releases described in this paper represent the initial response to that need.

The reservation noted above was expressed too casually in terms of convectional pictures by stating that the disagreement might mean that the assumption $\sigma_{2}>\sigma_{1}$ was not valid in the polar cap $\left(\sigma_{2}=\right.$ Hall conductivity, $\sigma_{1}=$ Pedersen or direct conductivity transverse to $\underline{B}$ ). The measurements reported here do indeed clearly show that the polar cap magnetic disturbance cannot be primarily attributed to Hall currents in the form of an overhead ionospheric sheet current. However, they also show than an explanation for this disagreement cannot be a consequence of neglecting horizontal currents proportional to $\sigma_{1}$, or assuming $\sigma_{2}>\sigma_{1}$ might not be valid. Figure 1 illustrates this point and provides a convenient reference for later discussion. (a), (b), and (c) of Figure 1 show the vector relationships between the $\underline{Z}=-\underline{V} \times \underline{\sim}$ convection and the horizontal disturbance, $\underset{\mathrm{H}}{\sim}$, that would be produced by model ionospheric currents when different relative importance is attached to the Hall current, ih $\left(\propto \sigma_{2}\right)$, and Pedersen current, $i_{p}\left(\propto \sigma_{1}\right)$. Cowling currents, proportional to $\sigma_{1}+\sigma_{2}^{2} / \sigma_{1}$, are omitted in that their vector properties relative to $\underset{\sim}{\mathrm{E}}$ and $\underset{\sim}{\Delta}$ are identical to those of $i_{p}$. They would, of course, only exist if a non-uniform ionosphere was introduced in the idealization. The idealization also ignores questions of continuity such that magnetic effects shown for ip are just those from the ionospheric portion of a Pedersen current circuit. Auroral belt observations would, for example, be best represented by F'igure I(a)--omitting reference to the sun vector. Figure 1 (d) illustrates, in advance of the data presentation, the relationship between $\mathrm{V}$ (or $\underset{\sim}{\mathrm{E}}$ ) and $\Delta \mathrm{H}$ that was typically 
observed in the polar cap experiments. $\underset{\sim}{\sim}$ does not parallel $\Delta \mathrm{H}$, as expected for Hall currents, and the difference between models and observations increases if there is any contribution to $\Delta H$ from an overhead $i_{p}$.

The most common explanation for the cause of the polar cap disturbance was thus contradicted by the electric field measurements. Similarly a review of pertinent publications did not reveal any existing theories or models consistent with both these observations and the general properties of high latitude disturbances. The results thus opened a new mystery and a number of different approaches were taken in seeking an explanation. Several of the attempted, but abandoned, explanations are briefly described to illustrate some of the constraints imposed by surface magnetic data.

These considerations finally led to a model that provides an explanation for the polar cap magnetic variations and also predicts characteristics of the auroral electrojet $\mathrm{Hall}$ currents and their closure that differ from past analyses known to us. Although still in a formative state that illustrates the need for additional proof, we believe that the framework for this model is sufficiently justified to be presented in outline form. The model not only requires the Hall current electrojets to be closed via field-aligned currents but also illustrates that such field aligned currents are a necessary consequence of electron density gradients in auroral regions. Recognition of the "real" ionosphere as opposed to past treatments using model ionospheres involving only large scale strips of enhanced conductivity leadș to basic differences. The usual assumption div ih $=0$ with $i_{h}$ continuity within the ionosphere and steady flow conditions in which spatial derivatives of the product $\mathbb{N}_{\mathrm{e}} \mathrm{E}$ remain zero simply do not apply. ... It is similarly necessaxy to contradict other concepts which have prevailed in analyses for many years. For example, abandoning overhead Hall currents as the cause of polar cap magnetic variations is readily supported on grounds that there 
is not experimental or theoretical evidence for assuming as in the past that the electron density in the polar cap ionosphere below $130 \mathrm{~km}$ is sufficient to support the required current. Nighttime middle latitude return paths for the auroral electrojet currents are also inadequate for ionospheric continuity of the electrojets because of both low electron density and the lack of an appreciable electric field.

The above remarks are indicative of the immediate consequences of these results. The implications relevant to associated phenomena are numerous. In this paper the intent is: (a) to present the measurements of magnitudes and directions of the polar cap electric field, (b) to note the uniformity of $\mathrm{E}$ relative to previous observations taken in and near aurora, (c) to note the consequences of these results relative to existing pictures for the cause of polar cap magnetic disturbances, and (d) to outline the initial framework for a new model of high latitude current systems that evolved to explain these . results but has broader implications related to the continuity of Hall current auroral electrojets.

\section{Method}

As the barium vapor technique and theoretical principles, by which the electric field $\underset{\sim}{\mathrm{E}}$ is deduced from $\underset{\mathbb{E}}{\mathrm{E}}=-\mathrm{V}_{\mathrm{i}} \times \underset{\sim}{\mathrm{B}}$ by measuring the horizontal velocity $V_{i}$ of the ion cloud, have been discussed in detail previously [e.g., Haerendel et al., 1967; Wescott et al., 1969] they are not repeated here. The reader is also referred to Wescott et al., [1969] for descriptions and discussions of the rocket payload, the reaction chemistry in generating the vapor clouds, the cameras and film types used for photography, triangulation techniques, and errors in data reduction. The previous descriptions for And $\phi y a$, Norway experiments are valid for the Cape Parry (Pin-Main) experiments because: identical canisters (a 3-Kg mixture of $25 \% \mathrm{CuO}, 74 \% \mathrm{Ba}$, and $1 \% \mathrm{Sr}$ ) were used, the nominal altitude 
spread for the four releases per rocket was similar $(200-300 \mathrm{~km})$, identical primary cameras $(\mathrm{K}-46$ aerial) were used, and identical procedures were used in obtaining individual data points from photographs. Differences between the Andфya and Cape Parry experiments and data presentations are noted where appropriate later.

The use of identical canister weights and chemical compositions as well as similar altitude ranges for the various releases is purposeful. Questions regarding method which are frequently asked are whether or not the results obtained are influenced by the neutral density (e.g., effect of the neutral wind on ion cloud motion vs. altitude) and whether or not the change in ambient ion density is sufficient to alter the ionospheric coupling in a manner that would effect the motion. If important one would expect these effects to introduce systematic differences with altitudè (i.e., comparing $200 \mathrm{~km}$ releases with $300 \mathrm{~km}$ releases) and time (i.e., comparing motions during the first few minutes following a release with motions 10 to 20 minutes after a release). Comparing only a few clouds could be quite misleading because of the great variability of the electric field; however, with a large number of similar samples the effects, if real and significant, should repeatedly occur. Although we have not subjected the data to fine statistical tests for such effects and thus cannot state that they are completely negligible, recognizable differences between clouds at 200 and $300 \mathrm{~km}$ have not appeared and similarly there is no indication that the ion clouds on the average move either faster or slower during the first few minutes following a release than at later times. It appears probable that lower altitudes and greater release weights would be required for these effects to have an appreciable: influence. An additional potential advantage of holding the release weights, composition, and altitudes constant is that ultimately one can study features such as the formation of striations, the cloud elongation along field lines, etc. relative to geophysical conditions, independent of release variables. 


\section{Flight Conditions}

The polar cap releases were conducted by placing a portable launcher at the Cape Parry (Pin-Main) Dewline station in the Northwest Territories of Canada. Cameras were installed at this site and at the two Dewline stations, Pin-l and Pin-2, located, respectively, at Clinton Point and Cape Young. These locations and locations of the four releases from each of the three Nike-Tomahawk rockets are shown in Figure 2. Four K-46 aerial cameras, two all-sky cameras, and a three-component magnetometer were operated at Pin-Main, three $K-46$ aerial cameras and one all-sky camera were operated at Pin-l; three $\mathrm{K}-46$ aerial cameras, one all-sky camera, and a three component magnetometer were operated at Pin-2. $\mathrm{K}-46$ exposure times of 2,6 , and 12 seconds were sequenced three times per minute for a total of nine frames per camera per minute. All cameras were synchronized to within a fraction of a second. All-Sky camera exposures of $4,2,8$, and.2 seconds were sequenced three times per minute for a total of twelve frames per camera per minute.

Clouds were distributed horizontally by having the first and last two releases, respectively, along the ascent and descent legs of the rocket trajectories. Actual altitudes for the releases are given in Table 1 . .

Table 1: Release altitudes (in $\mathrm{km}$ )

Flight 1 Flight 2

Cloud I

Cloud 2

CIoud 3

Cloud 4
221

286

286

210
218

274

276

189
210

263

257

168 
Two flights took place in evening twilight and one during morning twilight. This distribution permitted sampling at two widely separated magnetic times. The three flights occurred on successive UT days, March 7, 8, and 9, 1969, and moderate magnetic disturbance conditions were present for each flight. The nine hour periods centered on the three hour periods during which each flight took place had the following 3-hour Kp indices: Flight 1 (2, 3+, 4--), Flight 2 $(3,3,2-)$, and Flight $3(2+, 3-, 2)$. Thus, for sucçessive flights the 3-hour Kp indices of 3+, 3, and 3- are indicative, like the nine hour periods, of sequentially a slightly decreasing level of disturbance.

Latitudinal displacement, or distance, from regions of auroral activity is probably the most meaningful criterion for knowing that a polar cap environment is being sampled as opposed to an auroral belt environment. The surface magnetic disturbance is less discriminating for stations not greatly displaced from the auroral electrojet, in that the electrojet current can produce a magnetic effect, principally in the $Z$ component, at distances of 500 to $1000 \mathrm{~km}$. Figure 2 shows the location of the aurora closest to the release area during and near the times when drift observations were being taken. It is apparent that the releases during the first two flights were greatly displaced from the simultaneous auroral belt whereas during the third flight the aurora moved northward and approached the ion clouds. It is thus questionable, as noted later, to treat the third flight as a representative polar cap observation.

Magnetic field data from relevant observatories were reduced with considerable care and vector disturbances were transformed to magnetic time and latitude coordinates. Quiet day baselines for determining the disturbance vectors-are... believed to be highly accurate. These were derived from selected periods within two nearby exceptionally quiet (i.e., QQ) days, March 3 with a daily Kp sum of 4 and an 18 hour period on March 4 when the 3-hour Kp remained at 0. 
Flight 1, March 7, 1969

The first flight took place during morning twilight at a time when no aurora was visible from any of the three Pin stations during launch preparations and throughout the period of $\mathrm{Ba}^{+}$cloud tracking. As shown in Figure 2 aurora did appear near the southern horizon of Pin-Main several minutes after tracking of the $\mathrm{Ba}^{+}$clouds was no longer possible. The distance from auroral activity was thus $>6^{\circ}$ in invariant latitude for all clouds throughout the data interval.

Figure 3 shows triangulated locations of the four $\mathrm{Ba}^{+}$clouds vs. time projected along magnetic field lines to a common reference plane at $100 \mathrm{~km}$ altitude. Relative to auroral zone releases where the clouds frequently become highly striated and break-up or spread out with increasing dimensions, these clouds remained compact with only several major striations per cloud. Thus, it was generally not necessary to triangulate separately on different portions of a cloud. Exceptions occur between 13:19:40 and 13:23:00 UP for cloud 1 and following 13:22:00 UT for cloud 2 as noted by connecting lines in Figure 3 . As visually observed, the clouds, in addition to appearing compact, had the appearance of moving in parallel formation across the sky. $\because$. The location of the tracks in magnetic time and geomagnetic latitude coordinates is shown in Figure 4 together with the magnetic disturbance present at the time of the fourth barium release. The uniformity of the horizontal component of the polar cap magnetic disturbance when plotted in magnetic time and either geomagnetic or invariant latitude coordinates, as opposed to use of either local time or geographic coordinates, is a well known property of the polar cap disturbance except during periods of very weak electrojet activity [Heppner, 1967a]. The uniformity of vectors at latitudes $>80^{\circ}$ on the day-side and $>72^{\circ}$ on the night-side evident in Figure 4 is typical for the polar cap. It is also typical for $+\Delta z$ and $-\Delta Z$, respectively, to be largest at polar cap 
stations closest to negative and positive bay auroral electrojet regions and to diminish in intensity toward the center of the polar cap. This has been demonstrated statistically in an unpublished analysis and is to be expected when the electrojets are intense such that they contribute to the polar cap $\Delta \mathrm{z}$. Exceptions to the $\Delta Z$ statistics at individual observatories at isolated times are, however, numerous and thus cases which disagree, such as $\Delta z$ at Mould Bay near $1^{\mathrm{h}} 30^{\mathrm{m}}$ and $79^{\circ}$ in Figure 4 (also see Figure 5), are not surprising. The exceptions, in $\Delta Z$ in particular, but also appearing as fractional effects in $\Delta \mathrm{H}$ could be interpreted as indicating local variations in an overhead ionospheric current. We doubt that this interpretation applies. Local or regional deviations from uniformity are likely to be caused by earth induction effects. They could also result from the superposition of fields from a nonuniform distribution of field aligned currents completing electrojet circuits as discussed later. The principal point here is to note that use of the word "uniform" is relative and that it does not exclude fractional differences between observatories.

Figure 5 shows the polar cap magnetic disturbance throughout the interval of $\mathrm{Ba}^{+}$cloud observations. ${ }^{\Psi} \Delta \mathrm{H}$ is the horizontal angle between the $\Delta \mathrm{H}$ disturbance vector and the direction of the sun as illustrated in Figure 1 . The naxrow ranges for $\Psi_{\triangle \mathrm{H}}, \Delta \mathrm{H}$, and $\Delta \mathrm{Z}$ for Mould Bay, Resolute Bay, Alert, and Thule (except for $\Delta z$ at Mould Bay) are indicative of what is meant by a uniform disturbance. The Pin-Main and Pin-2 disturbance values are similar but it is apparent that they are contaminated by the superposition of a field from the auroral electrojet to the south.

The total E vector, calculated from $-\mathrm{V} \times \underset{\sim}{\mathrm{B}}$, is described by $|\mathrm{E}|$ and $\Psi_{\mathrm{F}}$, the horizontal angle between $\underset{\sim}{\mathbb{E}}$ and the direction of the sun, in the absence of magnetic field aligned electric fields. The fact that fall rates, altitude vs. 
time, for the $\mathrm{Ba}^{+}$clouds were normal (i.e., the same as for the neutral clouds) justifies showing the vector only in the horizontal plane as well as the assumption that the magnitude of $\underset{\sim}{\sim}$ along $\underset{\sim}{\mathrm{B}}$ is negligibly small. The curves for $E$ and $\Psi_{\mathrm{E}}$ Vs. time in Figure 5 have been smoothed as a function of time as described below.

It is obvious, and observed in practice, that the roughness of $\mathrm{E} v \mathrm{v}$. time curves from the $\mathrm{Ba}^{+}$cloud motions is in part determined by the time interval between position determinations; that is, dividing a small displacement in location by a small interval of time (e.g., 10 seconds) gives a determination of $\mathrm{V}$ subject to small errors in the position determination. A sawtooth curve is often the result but errors can be more subtle. At the other extreme, using positions widely separated in time (e.g., several minutes) does not permit determination of smaller scale variations in $\underset{\sim}{\mathbb{F}}$. From direct probe measurements of the electric field [Aggson, 1969; Maynard and Heppner, 1970; Gurnett, 1970] as well as the $\mathrm{Ba}^{+}$data, the time-space spectra of the $\underset{\sim}{\sim}$ field is known to extend to very small dimensions. Thus in using long time intervals the small scale variations are not only lost but a false impression of uniformity is given. An ideal compromise between resolution and erroxs is seldom easy to determine because both the irregularities and errors are variables from flight to flight, cloud to cloud, and with time during the movement of a given cloud. As our primary interest in this paper is in the bulk motion the following smoothing technique was used for Figure 5. The velocity vector, $V$, was in general determined over one minute intervals three times per minute by using positions successively from $00^{s}$ to $00^{s}, 20^{s}$ to $20^{s}$ and $40^{s}$ to $40^{s}$. Where a position determination was missing at $00^{\mathrm{s}}, 20^{\mathrm{s}}$, or $40^{\mathrm{s}}$ either positions displaced by $10^{\mathrm{s}}$ were used or the velocity was calculated over 2 minutes. Thus, three independent curves for $\mathrm{E}$ and $\Psi_{\mathrm{E}}$ were produced for each cloud. These three curves were then 
averaged to give the curves shown in Figure 5 for each cloud. The differences between individual curves and the average curves of Figure 5 provide an approximate measure of the combined magnitude of irregularities and position errors washed out by the smoothing process. For th these differences were $<5$ volts $/ \mathrm{km}$ except for a few isolated points occurring mainly at the end of the observation period. For $\Psi_{E}$ differences were $<10^{\circ}$ except for an isolated interval near $13^{h_{2}} 3^{m}$ for cloud 2 and several points near the end of the observations.

In total, the above implies that the differences, exceeding 5 volts $/ \mathrm{km}$ and $10^{\circ}$, between clouds or along the curve for a single cloud are real. Considering first the curves for the magnitude of $\underset{\mathbb{E}}{\sim}$, the reader, observing the bumpiness but unfamiliar with past E field measurements, may find it difficult to recognize that these curves represent a relatively uniform $\mathrm{E}$ field. However, out of 15 high latitude flights these curves, and those for flight 2 in this series, represent the most uniform space-time behaviors encountered. . The magnitude is clearly centered, but variable, within the range 20 to 40 volts $/ \mathrm{km}$. Although the polar cap $\Delta H$ was gradually increasing over the data interval there does not appear to be a time gradient in the magnitude of $\mathrm{E}$.

The time-space variability of $\Psi_{E}$ is more complex, particularly because of the change centered on the interval $13^{\mathrm{h}} 22^{\mathrm{m}}$ to $13^{\mathrm{h}} 23^{\mathrm{m}}$ which is most apparent in the $\Psi_{\mathrm{E}}$ curve for cloud 2. Noting also that the orientation of clouds 1 and 2 apparently changed near $13^{h} 22^{m}$, or alternatively the clouds split, such that multiple positions could be determined (see Figure 3), the smoothed $\Psi_{E}$ curves at this point do not provide sufficient resolution to follow the exact sequence. of change. The important thing to note for the present is that a sudden change in $\Psi_{\mathrm{E}}$ did take place and that there is not a corresponding sudden change in $\Psi_{\Delta H}$ at the polar cap stations. This provides one of several arguments against attributing the polar cap disturbance to overhead ionospheric currents. 


\section{$-12-$}

The sudden change in $\Psi_{E}$ does, however, coincide within \pm 1 minute to the sharp onset of a negative bay at Pt. Barrow. As illustrated by the vectors at $13^{\mathrm{h}} 19^{\mathrm{m}}$ in Figure 4 a negative bay was present at College, Alaska (near o2h and $65^{\circ}$ ). The bay began gradually before $13^{\mathrm{h}} 00^{\mathrm{m}}$ and continued to increase in intensity until a maximum was reached near $13^{\mathrm{h}} 4^{\mathrm{m}}$. However, at Pt. Barrow (near $00^{\mathrm{h}} 4^{\mathrm{m}}$ and $69^{\circ}$, Figure 4) there was relatively little activity prior to $13^{\text {h }} 22^{m}$ at which time there was a sharp break toward large $-\Delta \mathrm{H}$ values. Examination of other high latitude observatories illustrates that the complete data period was one in which electrojet activity was increasing toward greater bay deflections but only Pt. Barrow shows the sharp change. Thus, a local enhancement occurred near midnight and the fact that aurora became visible on the south horizon of Pin-Main after $13^{\mathrm{h}} 35^{\mathrm{m}}$ indicates, along with the activity at College, Alaska prior to $13^{\text {h }} 22^{m}$, that aurora was advancing northward with the increase in activity. The simultaneous (i.e., within \pm 1 minute) change in $\Psi_{\mathrm{E}}$ and the bay onset at Pt. Barrow is not likely to be pure coincidence. Interpretation is not obvious although it is easy to speculate and attempt to relate this event to the concepts of regional collapse of the magnetospheric tail previously advanced from magnetic field data [Heppner, 1967b; Heppner, et al., 1967]. However, this one example involving E field data is not sufficient to expand the present analysis into a discussion of models for partial collapse of the magnetospheric tail.

The most pertinent feature of the data, for this paper, is the displacement between $\Psi_{E}$ and $\Psi_{\Delta H}$. As stated in the introduction these angles should coincide if the polar cap disturbance is caused by Hall currents in the form of an ionospheric sheet. Also, as stated and illustrated in Figure '1, Pedersen or Cowling currents contributing to an ionospheric sheet current would create a discrepancy between $\Psi_{\mathrm{E}}$ and $\Psi_{\Delta \mathrm{H}}$ of opposite sign to that observed. 
Flight 2, March 8, 1969

Flight 2 took place during local evening twilight with aurora present only near the south horizon as shown in Figure 2. As in the case of Flight I the distance between the closest $\mathrm{Ba}^{+}$cloud and the northernmost aurora was always $>6^{\circ}$ of invariant latitude.

Figure 6 shows the triangulated and projected locations of the four $\mathrm{Ba}^{+}$ clouds vs. time. As suggested by the multiple points shown at $20^{5}$ intervals the principal striations became separated by greater distances for these clouds than for the clouds of Flight 1 . They did not, however, disperse greatly. Individual principal rays maintained identity for a number of minutes and velocity differences between rays were in general small as noted later.

The location of the tracks in magnetic time and geomagnetic latitude coordinates is shown in Figure 7 together with the magnetic disturbance present at the time of the cloud 4 release. The uniformity of the polar cap magnetic disturbance is similar to that for Flight 1 at the very high latitudes and the disturbance at the Pin stations is again influenced by the electrojet activity in the south. The $-\Delta \mathrm{Z}$ values at Pin-Main and Pin-1 (also see Figure 8 ) are . consistent with the disturbance vector expected at these observatories from the positive bay activity at latitudes $<70^{\circ}$. The magnitude of $\Delta \mathrm{H}$ at Pin-Main and Pin-1, relative to other polar cap stations is not, however, consistent with having a $\Delta H$ contribution from a simple horizontal electrojet flow to the south. Again, for explanation, one could invoke variations in an overhead ionospheric current but in doing so, conflicts with other features of the data appear. Although unique models are impossible we consider it to be reasonably likely that the fractional discrepancy can result from the superposition of fields from a non-uniform distribution of field aligned currents in the auroral belt. In this particular case this appears to be a more likely explanation for the $\Delta H$ 
difference than a local earth induction explanation: primarily because of the similarity at Pin-M and Pin-l and the indication that the disturbance at Mould Bay (the next closest station, near $15^{h}$ and $80^{\circ}$ in Figure 7 ) is transitional between the disturbance characteristics at the Pin stations and the rest of the polar cap. It should be kept in mind, however, that earth induction effects will always cause some differences between stations. Figure 8 illustrates the disturbance throughout the observing period. From the $\Psi_{\Delta \mathrm{H}}$ curve for Alert it might appear that the uniformity of the polax cap disturbance breaks down over the interval showm; howevex, this is probably misleading in that the large deflections appear as $\Delta H$ becomes small and errors of only a few gammas in baseline determinations will produce large differences in ${ }_{\Delta \mathrm{H}}$.

The $\mathrm{E}$ and $\Psi_{\mathrm{E}}$ curves of Figure 8 result from both a time and space smoothing of the data in that velocity vectors were computed separately for each principal ray that maintained identity over several or more minutes of time. As described for Flight 1, velocities were computed over one minute intervals three times per minute: $00^{\mathrm{S}}$ to $00^{\mathrm{S}}, 20^{\mathrm{S}}$ to $20^{\mathrm{S}}$, and $40^{\mathrm{S}}$ to $40^{\mathrm{S}}$. Thus for a given cloud at a given time, 3 ( 1 ray), 6 (2 rays), or 9 ( 3 rays) curves for $E$ and $\Psi_{\mathbb{E}}$ were produced. The mutiple curves for a given cloud were then averaged to give the curves shown in Figure 8. Differences between the individual curves and smoothed curve for a given cloud were typically $<3$ volts $/ \mathrm{km}$ and $<10^{\circ}$ over much of the time. Notable exceptions with larger differences appeared between $3^{\mathrm{h}} 30^{\mathrm{m}}$ and $3^{\mathrm{h}} 3^{\mathrm{m}}$ (cloud 2), $3^{\mathrm{h}} 27^{\mathrm{m}}$ and $3^{\mathrm{h}} 30^{\mathrm{m}}$ (cloud 3 ), and near $3^{\mathrm{h}_{32^{\mathrm{m}}}}$ (cloud 4 ).

The differences between the smoothed curves for the four clouds, Figure 8, are in general similar or only slightly greater than the differences between

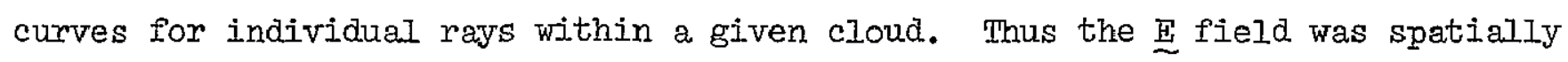
similar over the area sampled. Time variability is, however, indicated--particularly by the average increase in magnitude and the decrease in $\psi_{\mathbb{E}}$ centered near $03^{h_{29}}$. Correlated time changes in the polar cap $\Delta \mathrm{H}$ are not apparent. It is 
also not apparent that small scale changes in the auroral belt to the south can be correlated with the E field changes.

The displacement between $\Psi_{\mathrm{E}}$ and $\Psi_{\Delta \mathrm{H}}$, roughly $60^{\circ}$, is larger than in the case of Flight I but both flights show the same sign discrepancies relative to ionospheric current models.

\section{Flight 3, March 9, 1969}

Flight 3, like Flight 2, took place in evening twilight but in this case the northernmost aurora was near $\Lambda=73^{\circ}$ at the time of the first release near $\Lambda=76^{\circ}$, see Figure 2. The aurora moved slowly northward to $\Lambda=75^{\circ}$ to $76^{\circ}$ during the tracking period. During the same period the $\mathrm{Ba}^{+}$clouds moved to $\Lambda>77^{\circ}$ and to the east such that a distance $\geq 200 \mathrm{~km}$ separated the $\mathrm{Ba}^{+}$clouds and visual aurora at closest approach. The complicated behavior of these clouds relative to Flights 1 and 2 indicates, however, that this separation was not sufficient to regard the $\underset{\sim}{\sim}$ field as being typical of the polar cap. The scatter of triangulated locations vs. time in Figure 9 is indicative of the complex paths followed by some of the major rays. Visually, the clouds appeared initially to move smoothly but multiple striations developed rapidly and major segments moved apart within each cloud. Subjectively, observers received the impression that the clouds were breaking apart in response to the northward movement and development of aurora to the south and west.

Figure 10 shows the vector magnetic disturbance at the time of the fourth release. Magnetic field variations at polar cap stations throughout the data interval are given in Figure 11. Although weaker than during the first two flights the uniformity over the polar cap is not greatly different in terms of. differences in $\Delta H$ and ${ }^{\Psi} \Delta H$ between observatories. The disturbance at Pin-Main and Pin-l was obviously affected by the positive bay electrojets associated with auroral activity to the south. As the aurora advanced northward the Pin-Main 
and Pin-1 horizontal disturbance vector rotated northward such that it more closely resembled the positive bay disturbance at the auroral belt stations. Except for this local effect caused by proximity to the aurora the polar cap magnetic field remained relatively constant throughout the data interval. Auroral belt magnetograms do not show any remarkable changes, except that at Ft. Churchill (near $20^{\mathrm{h}} 30^{\mathrm{m}}$ and $69^{\circ}$ in Figure 9) the positive bay disturbance had a relatively sharp maximum at $03^{h_{41}} \mathrm{~m}$.

The $E$ and $\Psi_{E}$ curves of Figure 11 were smoothed in space and time by the same technique as described for Flight 2; however, in the case of cloud 2, and for a more limited period fo time for cloud 3, the major rays were too widely separated to justify avexaging their motions. Thus, separate time averaged curves are shown for these cases. An explanation for cloud 2 becoming so widely dispersed relative to clouds $I$ and 3 is not obvious but does not present inconsistencies relative to the general variability of the $\Psi_{\mathrm{F}}$ curves which implies rather extensive twisting of the general E field. Cloud 4 was only tracked for a short period of time before passing out of the region of solar illumination. However, its velocity was anomolous relative to the other clouds. This suggests a spatial change in the $\underset{\sim}{\mathbb{N}}$ field between clouds 3 and 4 rather than a higher latitude continuation of the same space-time variability.

For clouds 1,2 , and 3 the average $E$ magnitude decreased between $3^{\mathrm{h}} 45^{\mathrm{m}}$ and $3^{\mathrm{h}} 4^{\mathrm{m}}$ from values of 20 to 30 volts $/ \mathrm{km}$ to values more in the range 10 to 20 volts $/ \mathrm{km}$. It is not apparent that any correlated change occurred in the magnetic disturbance. In experiments at auroral latitudes similar, but greater, decreases in $|E|$ are observed in and near strips of auroral luminosity. The aurora is not as close in this case so at most one can only conjecture that a Iower level of particle precipitation, too weak to produce a defined auroral form, may have extended to the north of the visible forms as they advanced. 


\section{$-17-$}

Regardless of the proximity to auroral activity and the various detailed differences between this flight and Flight 2, it is apparent that the large scale characteristics were not greatly different. Particularly the sign of the difference between $\Psi_{\mathrm{E}}$ and $\Psi_{\Delta \mathrm{H}}$ and the magnitude of this difference, roughly 40 to $80^{\circ}$, are in good agreement. In total the impression is that the polar cap E field was locally and transiently distorted in the region adjacent to active aurora.

\section{Summary of Electric Field Measurements}

Neglecting temporarily the implications regarding magnetic field variations, discussed in subsequent sections, the statements below provide a brief summary of the polar cap electric field results. It is important to note first that these results strictly apply only during times of moderate (i.e., Kp near 3) magnetic disturbance. These conditions were excellent for study of vector relationships but they do not permit answering questions regarding relationships between the magnitude of the polar cap $\underset{\sim}{\mathrm{E}}$ and other magnetospheric and ionospheric parameters.

1. The magnitude of $\mathrm{E}$ was typically within the range 20 , to 40 volts $/ \mathrm{km}$ for measurements in the invariant latitude range $74.5 \leq \Lambda \leq 79^{\circ}$ and separated from the northernmost aurora by a $\Delta \Lambda$ range $6^{\circ}<\Delta \Lambda<10^{\circ}$. Magnitudè differences between magnetic local times near $17-18^{h}$ and $2-3^{h}$, respectively were too small to be regarded as geophysically significant with the limited number of examples (see Flights 1 and 2 ).

2. The E vector was directed, roughly daw-dusk, at angles - ${ }_{\text {E }}$, relatively to the sun-earth line in the ranges: $40^{\circ}$ to $80^{\circ}$ at $2-3^{\text {h }}$ magnetic local time, and $80^{\circ}$ to $120^{\circ}$ at $17-18^{\text {h }}$ magnetic local time (see Flights 1 and 2 ).

3. The E field was more uniform both in space and time than $\underset{\sim}{\sim}$ fields typically encountered in the auroral belt. Small scale, fractional changes, in the $\underset{\sim}{\sim}$ field were, however, obvious. The time-space spectra 
of the irregularities did not appear to change greatly over distances of several hundred kilometers. This suggests a causal mechanism that exists over extensive regions (see Flights 1 and 2).

4. Flight 3 with a $\Delta \Lambda$ separation from aurora at $2-4^{\circ}$ as opposed to $\Delta \Lambda>6^{\circ}$ for Flights $I$ and 2 indicated that the general direction of the polar cap $\underset{\sim}{\mathbb{E}}$ did not differ for this proximity, but that: (a) the average magnitude of $\underset{\sim}{ }$ was less for the clouds closest to the region of auroral activity, and (b) the small scale space-time variations in $\underset{\sim}{\mathbb{E}}$ were much more pronounced. This behavior could be interpreted as indicating, either or both, a more turbulent source convection in magnetospheric regions adjacent to the auroral shells or ionospheric loading which would imply particle precipitation to the north of the advancing aurora. Inadequate models for $\Delta H$ in the polar cap

The measurements clearly show that the polar cap magnetic disturbance cannot be caused solely by Hall currents in the form of a horizontal ionospheric sheet current as frequently assumed in the past. Our first approaches toward interpretation were, however, based on the assumption that such a current did exist and was sufficiently intense to contribute to the $\stackrel{\Delta H}{\sim}$ disturbance [see Wescott, et al., 1970]. In fact, it appeared essential to have a polar cap Hall current to complete the auroral electrojet circuit. The polar cap disturbance, $\Delta H$ was thus considered to result from a vector addition, $\Delta H_{h}+\Delta H_{e}$, where $\Delta \mathrm{H}_{\mathrm{h}}$ was the Hall current component and $\Delta_{\mathrm{e}}$ was a component from an external (i.e., non-ionospheric) source. Continuity of the auroral electrojets required that the $\Delta \mathrm{H}_{\mathrm{h}}$ magnitude be a significant fraction of the total magnitude of the observed $\Delta H$. The geometry dictated by this consideration and the difference between the observed ${ }^{\psi_{\mathrm{F}}}$ and $\Psi_{\Delta \mathrm{H}}$ suggested that ${ }_{\mathrm{H}_{\mathrm{e}}}$ was roughly comparable in magnitude to $\Delta \mathrm{H}_{\mathrm{h}}$ and directed approximately toward the sun. The problem thus appeared to be one of finding the cause of a sunward directed $\Delta \mathrm{H}_{e}$. 
The problem also appeared to be predicted by model representations of the effects of bounding a uniform polar cap electric field by an auroral belt of enhanced conductivity as described by Vasyliunas [1970, also see references therein to similar models] even though it appears that these models deviate from observations in auroral regions. The net result of Vasyliunas' approach was that a $\Delta \mathrm{H}_{\mathrm{e}}$ would be produced by a circuit involving field aligned currents. The only geometrically satisfactory system of field aligned currents for producing a sunward $\Delta \mathrm{H}_{e}$, that we imagine, is one in which two field aligned sheet currents are centered in longitude, respectively, near $06^{\text {h }}$ (current into the ionosphere) and $18^{\mathrm{h}}$ (current out of the ionosphere). For uniformity of $\Delta \mathrm{H}_{e}$ over the polar cap the sheets must also extend in longitude over several hours of local time. These locations and signs for the field aligned currents are basically the same as drawn by Fejer [1961] and Akasofu [1970]. Haerendel and Iüst [1970] recognized this agreement and indicated that Akasofu's sheet current would resolve the discrepancy they found between magnetic perturbations in the polar cap and the polar cap

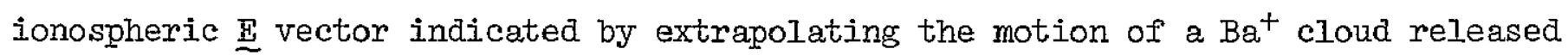
by the HEOS-I satellite at $12.5 R_{e}$. One should note, however, that: (1) Fejer [1961] connected his dawn and dusk field aligned currents with a polar cap Pedersen current, $\stackrel{i}{\sim}_{p}$, that would produce polar cap magnetic effects contrary to the results reported here, and (2) Akasofu [1970] connected his dam and dusk field aligned currents with an auroral electrojet band in which the ionospheric current is a Cowling current that is continuously westward from daw to dusk. Thus, Akasofu completely ignored the reversal of the electric field between morning and evening electrojet regions and other results from past auroral belt. experiments [see "Introduction" and references given there]. However, independent of these objections to the ionospheric circuits proposed to obtain continuity between dawn and dusk field aligned currents, it appeared obvious to us from 
various past analyses, and was further confirmed with new analyses, that field aligned sheet currents centered at $06^{\mathrm{h}}$ and $18^{\mathrm{h}}$ would produce magnetic effects on the low latitude side of the auroral electrojets that were not consistent with observation. Specifically, in the northern hemisphere between roughly $50^{\circ}$ magnetic latitude and the low latitude edge of the electrojet belt the disturbance vector would be dominantly westward and eastward, respectively, at $06^{\mathrm{h}}$ and $18^{\mathrm{h}}$. As described later this statistically disagrees with observation by roughly three hours and the statistics are borne out through study of many individual cases.

The above failure to explain a solar directed $\stackrel{\Delta \mathrm{H}_{e}}{\sim}$ by means of field aligned currents led us to search. for other causes. As this search did not result in finding an adequate $\underset{\sim}{\sim} \mathrm{F}$ we will note only several points which are pertinent to the polar cap problem. One attempt was to see if the polar cap disturbance might not be explained in terms of the fields produced by currents induced in the earth by the auroral electrojets. Although this seemed, and was, at most a remote possibility, the reason for giving it consideration is worth noting. That is, if one examines polar cap magnetic variations at times corresponding to large bay enhancements in auroral electrojet activity for periods such as one hour, the polar cap variations have the appearance of being strongly attenuated and filtered versions of the electrojet bays. For simple models this would be the expected appearance for field effects from currents induced at sufficient depth to be observed and appear relatively uniform over distances such as $1000 \mathrm{~km}$ (i.e., the earth beneath the electrojets would act as a low pass filter and the image induced currents for rapid changes would be locally confined). As noted in the next section, the distant, integrated field from a large number of field aligned current filaments is also likely to have this appearance. 


\section{- 21 -}

Explanation for a sunward directed $\Delta \mathrm{H}_{\mathrm{e}}$ was also sought in terms of the polar field produced by the combined effect of cavity confinement of the magnetosphere and magnetospheric inflation. The Mead [1964] and WiIliams and Mead [1965] models, for example, give sunward horizontal components of 2.2 and 3.2 garmas, respectively, at the poles. However, these models neglect internal magnetospheric plasma pressures for $R_{e}<10$ which are known to be large from the field inflation observed at low magnetospheric latitudes [e.g., Cahill, 1970; Sugiura, et al., 1970; Coleman and McPherron, 1970] and the exceptionally strong magnetospheric fields at higher latitudes [Sugiura, et al., 1970]. Inclusion of this inflation in cavity models would increase the computed sunward field at the pole in obtaining the same computer magnetopause configuration. Also, the observed strong magnetospheric fields at higher latitudes may be indicative that the real magnetopause at polar latitudes is significantily closer to the earth than computed. In total, the differences between the model magnetospheres and observed field distortions are of the type that would indicate a stronger sun= ward component in polar regions at the earth's surface. In pursuing an explanation for $\Delta \mathrm{H}_{\mathrm{e}}$ with these considerations we were not, however, able to justify a $\Delta_{e}$ magnitude sufficient to solve the polar cap problem. Nevertheless it is worth noting that the polar cap disturbance vector probably always contains a contribution from this source which will also vary with time. If an accurate estimate of its magnitude could be made it should be subtracted from the observed

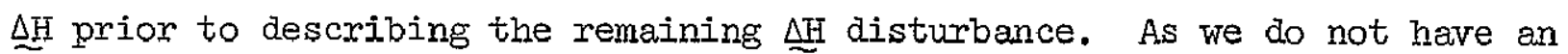
accurate estimate we regard it as a source of error for the present. The analysis by Nishida, et al., [1966] provides additional evidence for the influence of magnetospheric inflation and the possibility that this error may not be insignificant. 
Dynamo currents from ionospheric winds were not seriously considered as a possible cause for the polar cap $\Delta H$ on the simple grounds that the wind system would not only need to be uniform over a vast region but would also have to vary in phase with magnetic activity in auroral regions. A wind system that would satisfy both these criteria is difficult to imagine.

\section{Framework for a New Model}

Inability to explain the polar cap $\Delta \mathrm{H}$ by a vector addition $\Delta \mathrm{H}_{\mathrm{h}}+\Delta \mathrm{H}_{\mathrm{e}}$ is one factor that led us to question the significance of Hall currents in the polar cap. A second factor is the lack of correlation between detailed time changes in $\underset{\mathbb{E}}{\mathrm{E}}$ and $\Delta \mathrm{H}$. A third, more subtle, consideration is that there does not appear to be any logic based on either observation or theory for assuming that polar cap conductivities change in proportion to auroral electrojet changes. In theory, a proportionality in the magnetic disturbance could be maintained through equivalent changes in $\mathbb{E}$ but this requires unique relationships between the distant magnetosphere and the ionosphere which also cannot be logically justified. A fourth factor, related to the third, is that auroral zone experiments indicate that an electrojet current comparable to the current required for polar cap disturbances does not appear in the absence of visible aurora even when $\underset{\mathrm{E}}{\mathrm{E}}$ is of comparable magnitude.

The above, instigated a literature search for information regarding polar cap electron densities in the altitude range 100-130 km where the Hall conductivity is most effective. This revealed only that the density must be very low: definitely $<10^{4} / \mathrm{cm}^{3}$, but how much less appears to be unknown in that E-region reflections from ionosondes with sweep frequencies $\geq 1 \mathrm{mHz}$ disappear during the dark hours and at low solar angles [Penndorf, 1965]. Model calculations [Keneshea, et al., 1970; Lerfald and Little, 1970] indicate that.values near 
$10^{3} / \mathrm{cm}^{3}$ may be realistic. The possibility that a significant, wide spread, E-region ionization is created by particle influx also appears remote in view - of polar cap airglow measurements [Eather, 1969].

With these considerations the problem of interpretation, changes in that one is obligated to place $\underset{\sim}{\Delta} \mathrm{H}=0$ and explain the polar cap magnetic disturbance almost entirely in terms of an external source (i.e., $\underset{\sim}{\stackrel{\Delta}{*}} \doteq \underset{\mathrm{H}}{\Delta}$ ). Also, because this eliminates a major portion of the ionospheric circuit cormonly assumed for auroral electrojets it obligates one to take a new approach relative to the continuity of Hall currents in auroral regions. This new problem fortunately meshed well with other problems involving $\mathrm{Ba}^{+}$striations, the decrease in $\mathrm{E}$ associated with auroral forms, etc., with which we wexe simultaneously concerned relative to auroral belt data. In essence, by expanding the scale of considerations regarding the effects of small scale ionospheric irregularities on Hall current continuity it became apparent that Hall current electrojets could close by way of field aligned currents.

HALL CURRENT CONTINUITY: Figure 12 illustrates in simplest form the effect of a density discontinuity or gradient. In a uniform ionosphere, Figure 12 (A), convective motion of a flux tube transports electrons from position 1 to 2. Ions in the lower E-region of the ionosphere $\left(\nu_{i n}>\omega_{i}\right.$ where $\nu_{i n}=$ ion-neutral collision frequency, $\omega_{1}=$ ion gyrofrequency) are, however, restrained by collisions with neutrals such that their mean bulk velocity is small comparedto that for electrons which is for all practical purposes unattenuated relative to the convective $\mathrm{V}$. As is well known this difference in ion and electron velocities constitutes the Hall current. However, where there is a spatial change (or localized time change) in the plasma density, either current must flow along field lines or a net charge is developed. This fact is not new and has undoubtedly occurred to every investigator who has qualified his analysis 
with statements equivalent to "in the absence of horizontal conductivity gradients" [Vasyliunas, 1970]. Conductivity gradients are, however, one of the most obvious characteristics of the auroral belt ionosphere and it is doubtful that any analysis which ignores them can be meaningful. Nevertheless, applicable quantitative treatments of the continuity problem do not exist for either small or large scale gradients. We similarly cannot provide a quantitative analysis but we can use observational evidence to guide assumptions and concepts. For example, we believe it is safe to assume that the accumulation of a net charge, as illustrated in Figure 12, is relatively insignificant for most problems. By insignificant we mean that charge does not accumulate to the extent of producing a polarization $\mathbb{E}$ field comparable to the convective $\underset{\sim}{\mathbb{E}}$. This is perhaps not a surprising belief in that mechanisms for holding such a charge are also unknown. However, non-convective polarization fields are frequently proposed and if they exist and are sufficiently strong they will greatly change the flow. They are likely to be most effective on the scale of auroral ray cross-sections (i.e., several hundred meters) but, as noted by Heppner et al. [1970] in a companion paper where small scale features are treated in more detail, satellite E field measurements appear to rule out the possibility that small scale polar-

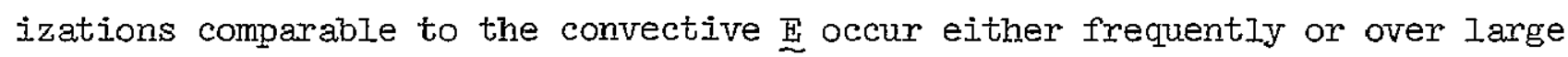
areas. Strong fields indicative of polarization at the boundaries of auroral forms are similarly not indicated by probe measurements or observed when the path of $\mathrm{a} \mathrm{Ba}^{+}$cloud crosses the shell of an auroral form. In total there is little or no evidence for, and considerable evidence against, taking approaches whereby Cowling and Pedersen conductivities would play as an important a role as the direct, $\sigma_{0}$, conductivity along field lines in examining the continuity of Hall currents at density discontinuities. 


\section{- 25 -}

The above does not mean that Pedersen, $\sigma_{1}$, currents are negligible in that they are always playing the role of trying to short circuit the convective $\mathrm{E}$ but it is not apparent that this affects the Hall current continuity as long as the charge accumulation remains small which must be true to have $\underset{\sim}{\mathrm{E}}$ and $\Delta H$ parallel as observed in the auroral belt. An interesting side point, but one which could only be documented through an extensive deviation from our principal topic, is that electrojet magnetic disturbances appear to be dependent on the ionization between $90-130 \mathrm{~km}$ (i.e., normal and 10w auroral heights) whereas ionization indicated by visible aurora at greater heights does not appear to be accompanied by an appreciable electrojet disturbance. This is to be expected from the theoretical height dependencies of $\sigma_{1}$ and $\sigma_{2}$ and explains why we speak of "plasma density at 100-130 km" rather than integrated conductivities. The model behavior we are considering would have little application in cases where the ionization was weak below $130 \mathrm{~km}$ but intense at 130 to $150 \mathrm{~km}$.

Figure 13 illustrates the continuity problem for a model geometry more applicable to the scale of electrojet currents. The condition $C>I$ which states that the electric field intensity or convective velocity, $\mathrm{V}=\mathbb{\mathrm { E }} \mathrm{B} / \mathrm{B}^{2}$, is less within the shell of enhanced density than in the adjoining regions is fundamental to stating the problem. It does not need to be regarded as an assumption as it has been repeatedly verified by measurements [e.g., Aggson, 1969; Wescott, et. al., 1970; and more recent unpublished observations]. The exact form of the northsouth density distribution is not critical but is drawn as shown to indicate that the density is enhanced and the velocity is diminished over a slightly greater dimension that the width of an auroral form.

Case I, lower left of Figure 13, shows the consequences of restricting the. current to the ionosphere. Case 2.A assumes that just enough field aligned current flows to prevent polarization distortion at the ends of the strip when 
the $\mathrm{C}=\mathrm{K}$ relationship approximately holds. As the implications for $\mathrm{C} \doteq \mathrm{K}$ are similar, we will examine these with reference to the more exact case 1 . $i_{\|}=0$ requires that the velocity (or electric field intensity) decrease in direct proportion to the increase in density. It also means that there is no concentration of current in the high density strip. The lack of an enhanced current in the high conductivity strip is readily recognized as being contrary to both measurements made by rocket-borne magnetometers near aurora and studies relating the position of aurora to the vector disturbance at the earth ${ }^{\top} s$ surface. It is not as obvious that having a relationship, $\mathbb{N} \propto I / E$, is objectionable because $\mathbb{E}$ measurements definitely do show a lower magnitude in regions believed to have a high $N$ from the existence of auroral Iuminosity. There are, however, several forms of argument against a simple inverse relationship. One, discussed later, is that observations indicate that $\Delta \mathrm{N}$ is more variable than $\Delta \mathrm{E}$. Another is. simply that there does not appear to be any logical basis for assuming that the electron density could be this closely tied to the electric field intensity in any model which assumes that the convection is driven by a solar wind interaction. A highly unique model would appear to be required. It is also apparent that extrapolation of the relationship $\mathbb{N} \propto 1 / E$ leads to the observational absurdity that $\underset{E}{2}$ becomes extremely large when the density drops to very low values. Thus a unique threshold condition for applicability of the model also becomes a requirement. The lack of any cause and effect relationships that would relate the existence of electrojets to increased ionization is another factor which makes one question the logic for Case 1 .

Case 2.B, Figure 13, represents a model behavior which we believe is more realistic for the large scale properties of auroral electrojets. Unlike Case 1 , in Case 2.B the logic is not as restrictive, there is agreement with observation, and cause and effect is implied. In region 1, Figure 13, remote from the density 


\section{$-27-$}

enhancement, or in the absence of any enhancements of the nightime ionosphere, it implies that the magnitude of $\mathrm{E}$ is representative of the driving convection uninfluenced by ion drag or Pedersen current shorting. Thus a weak $\underset{\sim}{\mathrm{E}}$ is permissible without increasing N. A concentration. of current in regions of high density is a necessary consequence for $(\operatorname{grad} \mathbb{N}) / \mathbb{N}>(\operatorname{grad} E) / E$ for gradients parallel to $\underset{\sim}{\mathrm{E}}$. As the implications, relative to observations, differ depending on whether one is considering an isolated strip as shown in Figure 13 or an assemblage of such strips over several degrees of latitude and several or more hours in local time, additional modeling of $E$ and $N$ is required. Also observational evidence that $(\operatorname{grad} N) / N$ is more variable than $(\operatorname{grad}$ E)/E, both parallel and perpendicular to $\underset{\sim}{\mathrm{E}}$, is required for the different scales involved.

For small scale features corresponding to rays with horizontal dimensions of 0.1 to $1 \mathrm{~km}$ and bundies of rays or diffuse patches with dimensions up to a few tens of kilometers, electron density measurements do not clearly permit distinction between Cases 2.A and 2.B [see Heppner, et al., 1970]. The measurement problem is akin to that of predicting $\Delta \mathbb{N} / \mathrm{N}$ from backscatter measurements [see, e.g., Unwin and Knox, 1968] and certain types of sporadic-E ionosonde reflections [see, e.g., Reddy, 1968].

For scales comparable to that of major auroral forms, one to several kilometers wide and several hundred to several thousand kilometers in length, typical electron densities and values for $\Delta \mathrm{N} / \mathrm{N}$ can be estimated from a combination of rocket measurements and expectations from luminosity relationships. Ideally the rocket measurements would be sufficient but there are very few cases for which both the rockets position relative to the aurora and calibrations are welr known. For example, the measurements by 'Reddy, et al., [1969] and Berthelier and sturges [1967] provide general information but are not definitive for this problem. Data with documented auroral information are most prevalent for cases where the rocket 
penetrated a region of diffuse glows and/or patches characterizéd by International Brightness Coefficient (IBC)-I. In these cases [Jespersen, et al., 1969; Baker, et al., 1967] values of $\mathbb{N}=2$ to $5 \times 10^{5} / \mathrm{cm}^{3}$ are typical. Two flights, one by McNamara [1969] and the other by Baker, et al., [1967] are particularly interesting in that discrete forms were encountered on one leg of the trajectory with the other leg falling outside the discrete form for comparison. In McNamara's case a peak value of $\mathbb{N}=9.5 \times 10^{5} / \mathrm{cm}^{3}$ was found within a visual band at $107 \mathrm{~km}$ with a half-maximum thickness of $7 \mathrm{~km}$ with an auroral, $5577 \AA$, brightness estimated to be 50-70 kR (i.e., an IBC between II and III). N outside the band on the other leg was $1.5 \times 10^{5} / \mathrm{cm}^{3}$. In the Baker, et al., [1967] case a somewhat broader maximum with a peak intensity of $6.5 \times 10^{5} / \mathrm{cm}^{3}$ at $113 \mathrm{~km}$ was found in an IBC-II aurora, and $\mathbb{N}$ on the other leg of the trajectory fell below $10^{5} / \mathrm{cm}^{3}$. These values can be compared with the relationship $\mathbb{N}=\mathrm{k}$ (brightness) ${ }^{\frac{1}{2}}$, found by Heppner [1954], for which values of the proportionally constant, $K$, have been determined by a number of investigations most recently summarized and presented in tabular form by Omholt [1966] and Dalgarno, et al., [1965]. The rocket measurements noted above are in reasonable agreement with the tabulations of NV vs. IBC but rather systematically indicate that the tabulated values of $\mathbb{N}$ should be multiplied by roughly 2. This could result from visual and photometric errors in obtaining brightness estimates during rocket flights. F'or our purpose here it means that we are only likely to underestimate values for $\mathbb{N}$ in using the IBC tables as a guide.

On the above basis conservative values are: $\mathbb{N}=10^{5} / \mathrm{cm}^{3}$ for moderate intensity discrete forms, $N=10^{5} / \mathrm{cm}^{3}$ for glows and the fringe regions of discrete forms, and $\mathrm{N}<10^{4} / \mathrm{cm}^{3}$ for regions remote from auroral excitation. The latter figure, $<10^{4}$, could easily be as low as $10^{3} / \mathrm{cm}^{3}$ below $130 \mathrm{~km}$ as noted previously. 
Magnitudes of $\underset{\mathrm{E}}{\sim}$ are not as readily categorized relative to auroral activity. One of the principal results of auroral belt measurements has been that there is not any simple relationship between $|\mathrm{E}|$ and the magnetic disturbance and both Haerendel and Lihst [1970] and Wescott, et al., [1970] concluded that the conductivity plays a more important role than $|\mathrm{E}|$ in determining the current intensity. This by itself favors the Case 2.B model; however, the observations permit a somewhat more quantitative approach. In particular, in all cases $|\mathrm{E}|$ has been observed to be weak when measurements were made within the magnetic shell of an auroral form. Typical magnitudes determined are $\leq 10$ and $\leq 5$ volts $/ \mathrm{km}$. The converse, that $|E|$ is always large away from active shells, does not hold in that values $>100$ volts $/ \mathrm{km}$ and $<5$ volts $/ \mathrm{km}$ have been observed at horizontal distances of roughly 25 to $100 \mathrm{~km}$ from the shells of visible aurora. However, if one omits extremes, which can probably be attributed to variations in the unloaded (i.e., driving) convection without affecting the arguments here, the range 10 to 50 volts $/ \mathrm{km}$ can be regarded as typical for regions remote from visible aurora but within and adjacent to the general belt of nighttime auroral activity.

In general this implies that $|\mathrm{E}|$ most commonly varies by a factor $\leq 10$ between highly conducting and poorly conducting regions. This is to be compared with the factors of 10 and 100 to 1000 for the variability of $\mathbb{N}$ between a highly conducting strip and, respectively, the fringe regions and remote regions noted previously. However, within the range of variability there may well be times when Case 2.A is more representative of a local behavior than Case 2.B, Figure 13 . At these times, or when and where there is sufficient diffuse particle precipitation to produce an ionization $\geq 10^{5} / \mathrm{cm}^{3}$ below $130 \mathrm{~km}$ surrounding discrete forms it is feasible to locally have $i_{\|} \rightarrow 0$ and $i_{1} \rightarrow i_{2}$. When and where this occurs the local electrojet geometry will more closely resemble a latitudinally confined horizontal sheet current than a line current. This variability, between a Iine 
and confined sheet, in the local electrojet geometry has in fact been indicated by rocket measurements in the presence of multiple auroral forms [Burrows, et al., 1970]. In the most general case a behaviox somewhere between that of case 2.A and Case 2.B is to be expected on the local scale of an auroral form and its immediate surroundings.

Extending the above argument and the scale to several degrees of latitude and several hours in local time, such that more than one auroral form and longitudinal variations within a given form are included, and comparing this with adjacent regions lacking auroral ionization, the Case 2.3 behavior has to dominate. What this change of scale demonstrates is that the field aligned current is not confined to the regions of brightest aurora. Similarly, because it is the integrated difference between the field aligned flux of electrons and ions that gives rise to a field aligned current, it does not follow that the local ill. Will be directly proportional to the precipitation flux; instead the local ill will be

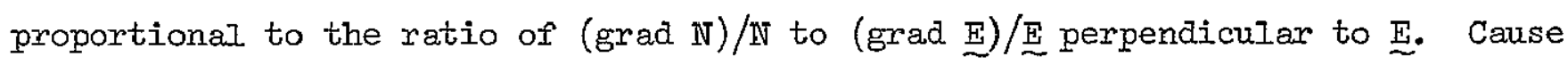
and effect is, however, clearly implied in that the distribution of grad $N$ is determined by the precipitation distribution.

Cause and effect becomes explicit on the scale of the entire electrojet belt as on this scale the integrated ionospheric Hall currents and field aligned currents will be nearly equal. The deviations from equality will be determined by the degree of continuity into polar cap and middle latitude regions and this we contend must be small on the night side of the earth. Thus, it becomes apparent that the existence of an intense auroral belt electrojet current depends on the availability of current from the magnetosphere. This is in agreement with an earlier contention, Aggson [1969], that the magnetosphere is more effective as a current generator than as a voltage source. 
For additional realism, and for future more quantitative modeling of the continuity, the Case 2.B illustration should be expanded to a variety of gradient representations. The purpose here has been to present the principles and the observations that make it apparent that this form of model applies.

FIELD ALIGNED CURRENT DISTRIBUTIONi: In the absence of ionospheric continuity of the Hall current either across the polar cap or by a middie latitude return path, the geometry for field aligned continuity to explain the polar cap $\Delta H$ must also be compatible with the $\underset{\sim}{ } \mathrm{H}$ disturbance observed on the low latitude side of the electrojet region. As stated earlier this simple test ruled out the possibility of centering field aligned sheets at $6^{\mathrm{h}}$ and $18^{\mathrm{h}}$ in magnetic local time to explain a solar directed $\underset{\sim}{\Delta}$ ever the polar cap. The same test, however, provides excellent agreement when the field aligned sheets are shifted to explain the total polar cap 새. As illustrated in Figure 14 (b) for the northern hemisphere the expectation is that to the south side of current sheets, appropriately oriented to give the polax cap $\Delta \mathrm{H}$, there should be a simultaneous magnetic disturbance that is most pronounced in the east ( $\mathrm{Y}$ ) component of the field with $+\Delta Y$ (i.e., east declination) and $-\Delta Y$ (west declination), respectively, to the south of current sheets "out of" and "into" the ionosphere. For an idealized geometry, taken to be representative of statistically average conditions such that random non-uniformities of the sheets disappear, the Y magnitude to the south should be $\leq \frac{1}{2} \Delta H$ as shown in Figure $14(\mathrm{~b})$.

Three approaches were taken to test these expectations: (1) simultaneous magnetograms from Canadian polar cap stations and North American observatories in the magnetic latitude range $54^{\circ}-62^{\circ}$ were examined to note their relative changes coincident with bay enhancements at the intervening auroral belt stations, (2) the computer generated vector disturbance movies described by Heppner [1967a] were studied, and (3) an entire year of 2.5 minute magnetogram scalings for 21 stations above magnetic latitude $50^{\circ}$ and including 6 stations between $50^{\circ}$ and $62^{\circ}$ 
was used in a computer program that picked, once per UT day, the magnetic local times of maximum $|+\Delta Y|$ and $|-\Delta Y|$ for each station and subclassified the statistics by the Kp disturbance level. As the results primarily substantiate conclusions that can more easily be reached using past analyses, as noted below, they will not be detailed here. All approaches indicated agreement with the $\Delta Y$ expectation in the pre-midnight sector, Figure 14(b). In fact this agreement is so general that mainly the exceptions, and the events they correlate with, become interesting for further study. Agreement with the $\Delta Y$ vector expected in the morning sector, Figure $14(\mathrm{~b})$, is not as clear. Sq variations and the variability of the dayside electrojet region influence the approach (3) statistics and approach (I) does not apply. The disturbance movies, approach (3) above, however, show that the vectors generally have a west declination (i.e., - $\Delta Y$ component) as expected.

Frequently quoted [e.g., Silsbee and Vestine, 1942; Nagata and Kokubun, 1960] statistical representations of equivalent current systems for bay disturbances, under labels such as SD and DS, provide excellent agreement with the vectors of Figure $14(\mathrm{~b})$. The reader may verify this by noting: (a) that a line draw parallel to the polar cap currents through the center of the polar plots is also parallel, within roughly \pm 1 hour, to the current drawn to lower latitudes from the regions of transition between westward and eastward auroral belt currents, (b) that the sign of the magnetic vector, Figure $14(\mathrm{~b})$, is consistent with the equivalent currents, and (c) that magnitudes as illustrated by the spacing between current Iines give a midale latitude $|\Delta \mathrm{Y}|$ slightly less than one-half the polar cap $|\Delta \mathrm{H}|$ in the late evening quadrant and a lessex magnitude for $|\Delta \mathrm{Y}|$ at the same latitudes in the late morning quadrant. In total, having current Iines entering and leaving the ionosphere at locations where they enter and leave the auroral belt in these representations gives a virtually similar disturbance pattern at 
extensively discussed by Heppner [1967a, 1969]. Similarly, keeping approximately the same local time distributions one could alter the latitudinal distribution of the evening sheet resulting from the net terminations without running into conflict with the observations. The mean orientation of the evening sheet in Figure 14(b) could, for example, be more east-west than that shown. The principal deficiency in a static picture here, however, is that relationships with grad $N$ and grad $\underset{\sim}{E}$ are obscure. Figure 14(a), for example, might suggest that the dashed Iine between the evening eastward and midnight westward currents represented a narrow zone of low electron density. Taken literally this would be misleading. Instead both the detailed convection pattern and the dynamic behavior in the region where current reverses has to be considered. In general this behavior is too complicated and poorly understood to dwell on here but in simplest form some insight is possible for the pre-midnight reversal region where there are $\mathrm{Ba}^{+}$cloud and auroral observations to indicate the dynamics. In simplest form one need only recognize that the convection, unlike the current, is continuous in that the east-west motion paralleling the conducting strips is a continuation of $a$ flow from higher latitudes. Figure $15(a)$ is an attempt to illustrate the principal by considering uniform conductivities, or densities, in the polar cap and auroral belt: respectively, densities $\mathbb{N}_{1}$ and $\mathbb{N}_{2}$ with $\mathbb{N}_{2} \gg \mathbb{N}_{I}$. In this case the boundary between the two regions becomes the ionospheric intercept of the field aligned currents, outward on the nightside and inward on the dayside. Figure $15(b)$ is a step closer to reality in that the uniform auroral belt is replaced by conducting strips drawn parallel to the convection. It is obvious that obtaining a sheet configuration similar to that of Figure $14(\mathrm{~b})$ from the principle illustrated by Figure $15(\mathrm{a})$ is primarily dependent on two factors: the distribution of precipitating particles producing ionization below $130 \mathrm{~km}$ and the detailed configuration of the auroral belt convection. A precipitation pattern 
latitudes $>50^{\circ}$. The statistical line of symmetry (i.e., a common perpendicular to the polar cap $\Delta \mathrm{H}$ and maximum middle latitude $|\Delta \mathrm{Y}|$ varies between different analyses: for example, roughly $8^{\mathrm{h}}$ to $20^{\mathrm{h}}$ in Silsbee and Vestine [1942], and a range from curvature of $8-10^{\mathrm{h}}$ to $20^{\mathrm{h}}-22^{\mathrm{h}}$ in Nagata and Kokubun [1960]. Placing the $\Delta \mathrm{Y}$ vector near $21^{\mathrm{h}} 30^{\mathrm{m}}$ magnetic local time in Figure $14(\mathrm{~b})$ is based on approach (3) statistics noted previously; the statistics however show a broad region, essentially $20^{\mathrm{h}}-24^{\mathrm{h}}$, in the late evening. A range of variability is to be expected not only from angle variability of the polar cap $\Delta H$ vector but also from the variability of the auroral belt transition regions between westward and eastward currents.

The fact that the normal to the polar cap $\Delta H$ vector intercepts the magnetic local time sector where the auroral belt $\underline{E}$ field and electrojet currents reverse is not likely to be just coincidental. As suggested by the Figure 14 illustrations, placement of sheet currents in the reversal regions gives an appropriate geometry for the magnetic disturbance. The late evening, time-latitude, boundary between eastward and westward Hall current belts in Figure 14 (a) is a rough average taken from the patterns given by Heppner [1969]. The Iate morning boundary between oppositely directed currents is not well defined [see Heppner, 1969] in the sense that the latitudinal overlap of eastward and westward currents appears often to be the reverse of that shown. Whether this morning hour variability is real or results from a lack of vector resolution is not known but this does not effect the time zone for placement of the sheet.

Although the geometry indicated by Figure 14 is appropriate we want it to be clear that a static, statistical picture of this type can not be literally interpreted in terms of the preceding continuity discussion. The time variability of the latitudinal overlap, particularly in the late evening sector, and occurrences of activity gaps between westward and eastward electrojet currents has been 
giving maximum ionization in the general regions of the electrojet current reversals would bias the Figure 15 (a) distribution toward that of Figure 14(b). Particle data, in terms of energy-spectra, pitch angles, and local time vs. latitude distribution are not comprehensive enough to indicate that there is a maximum in and near the current reversal regions. However, other indicators of the ionization such as auroral brightness, radio wave absorption, and peak values in the spatial distribution of magnetic disturbance all suggest maximum ionizing. precipitation near midnight coincident with and following time changes in the reversal region. Similarly, the existence of a pre-noon maximum in magnetic disturbances between $75^{\circ}$ and $80^{\circ}$ invariant latitude on the dayside is well known. These indicators favor biasing the Figure 15(a) distribution of field aligned currents toward that of Figure 14(b) but must be further related to the detailed convection pattern. Data regarding the convection pattern are sufficient to permit an idealization in the pre-midnight sector like that shown in Figure 15. The existence of currents with a large east to west component to the high latitude side of eastward currents preceding auroral break-up of the southernmost areas near midnight is well known [Heppner 1967a]. Moreover, $\mathrm{Ba}^{+}$clouds released near the reversal region provide examples of both north to south motion and the approximate reversal with latitude of the east-west component of motion indicated prior to $0^{\text {h }}$ in Figure 15 [Wescott, et aI., 1970; and unpublished data].

These factors give some basis for believing that a true average configuratior for the net field aligned current will not be greatly different from that of Figure 14(b) but some modifications and refinements can be expected in future analysis. The primary need for modification will probably stem from the obser: vation [Wescott, et al., 1970] that the motion of aurora in the break-up (i.e., field and current reversal) region does not, at least in some cases, parallel convective motions. This suggests precipitation by particles with sufficient 


\section{$-36-$}

energy to be effected by gradient and curvature drifts in the magnetosphere and means that convective motions with a large component normal to the conducting auroral strips will also need to be considered in a more comprehensive model involving the irregular spatial shifts of the pattern with time.

REIATED MAGNETOSPHERIC IMPITCATIONS: Obtaining a physical understanding of the magnetospheric current source and the continuity of current in the magnetoshperic equatorial plane is beyond the scope of the present study. However, the magnetospheric regions providing a, net flux of electrons or ions can be grossly defined. Figure 16 identifies these regions in terms of $90^{\circ}$ sectors which are adequate for discussion without involving models for magnetic field mapping. Continuity between these regions in the equatorial plane is drawn consistent with gradient and curvature drifts, westward for protons and eastward for electrons, and this gives the asymmetric ring current distribution described by Cummings [1966]. The agreement favors the model proposed here but a better understanding is needed before this can be taken as strong support.

Particle data, as stated previously is not comprehensive enough to permit identification of the integrated excess flux that gives a net field aligned current. Sharp, et al., [1969] found that the ratio of peak proton precipitation to that of electrons was much greater near noon than near midnight. This also favors our proposed model but as the comparison exists only for proton energies $>4 \mathrm{kev}$ and electrons $>0.08 \mathrm{kev}$ it can only be interpreted to be an indication of consistency. Extensive statistics for both electrons and protons extending down in energy to ten volts, or less, are needed for confirmation. The ISIS-I measurements of Heikkila and Winningham [1970] may apply. Preliminary analyses [Winningham, 1970] are particularly interesting in that they indicate that in the region where we place the dayside sheet current the energy spectra for both electrons and protons is identical to spectra observed in the magnetosheath. 
This raises the possibility that the inward current required on the dayside (Figure 16) could be coming directly from the solar wind. Whether or not this source or other apparent sources, such as the more recognized flux of electrons from the near-tail regions of the magnetosphere on the nightside, are most important remains to be determined. The risks of over simplifying the source, or current generating, problem can be appreciated by considering the feedback characteristics of the ionosphere. The Birkeland type model, which the preceding sentences might be assumed to imply with modifications, represents the extreme of no feedback in that current enters and leaves the auroral ionosphere without regard to any ionosphexic mechanisms. At the other extreme the role of precipitating, ionizing particles relative to electrojet currents is purely one of producing ionization and a pattern of electron density gradients; the energetic (i.e., ionizing) precipitation does 'not represent a net current and the electrojet and field aligned currents develop within the convecting field only as a consequence of the increased ionization and the gradients in the ionization pattern. The latter extreme is much closer than the Birkeland type model to the model we are proposing but we do not exclude the possibility that energetic particles contribute to the net current.

Summary of Rejected and Proposed Models to Explajn the

Polar Cap Magnetic Disturbance that Accompanies Auroral Electrojet Activity

1. The vector $\underline{E}=-\underline{V} \times \underline{\sim}$ determined from the. $\mathrm{Ba}^{+}$cloud motions, $\mathrm{V}$, was found to deviate by a large angle from the horizontal magnetic distrubance vector, $\Delta H$, such that $\Delta \mathrm{H}$ could not be attributed solely to Hall currents in the polar cap ionosphere. The deviation was of the opposite sign to that expected if ionospheric currents proportional to the Pedersen conductivity contributed to the disturbance. 


\section{$-38-$}

2. Initial efforts were directed toward explaining the polar cap $\Delta H$ in terms of a vector addition, $\underset{\Delta H}{\sim}=\Delta \mathrm{H}_{\mathrm{h}}+\underset{\sim}{\sim} \mathrm{H}$, where $\Delta \mathrm{H}_{\mathrm{h}}$ was a component attributed

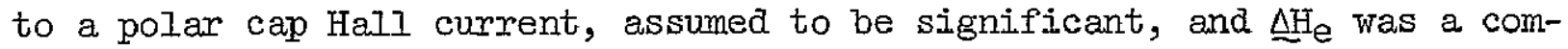
ponent attributed to an external (i.e., non-ionospheric) source. The geometry indicated that $\Delta \mathrm{H}_{e}$ would have to be of comparable magnitude to that of $\Delta \mathrm{H}_{\mathrm{h}}$ and directed roughly toward the sun. A cause for the $\underset{\sim}{\Delta \mathrm{H}_{e}}$ component was sought in terms of: magnetic field aligned sheet currents centered near $6^{\text {h }}$ and $18^{\text {h }}$ in the auroral belt, induced current effects, ionospheric winds, modifying models of the magnetospheric cavity to take into account magnetospheric inflation. All these approaches encountered serious diffi. culties. This led to questioning the significance of $\Delta \mathrm{H}_{\mathrm{h}}$ and on grounds that the electron density below $130 \mathrm{~km}$ in the polar cap was too low to support a substantial current two conclusions were reached: (a) that. practically all of the $\Delta H$ disturbance had to be explained in terms of a source other than overhead ionospheric currents, and (b) that continuity for Hall current auroral electrojets could not be obtained by the usual practice of assuming that the currents closed in the ionosphere over the polar cap and by return flow through middle latitudes regions on the nightside of the earth.

3. The framework for a new model, which is consistent in answering both the continuity and the polar disturbance questions, was developed. Factors involved included: (a) demonstrating that continuity for the Hall current electrojets could be achieved by way of magnetic field aligned currents, (b) demonstrating that placement of field aligned sheet currents "into" and "out of" the ionosphere, respectively, in the auroral belt magnetic time zones $8-12^{\mathrm{h}}$ and $20-24^{\mathrm{h}}$ was consistent with surface magnetic field observations, and (c) demonstrating that the conditions producing field aligned 


\section{$-39-$}

continuity for the Hall current electrojets were compatible with the placement of sheet currents. The relative magnitudes of (grad $N) / \mathrm{N}$ and (grad E)/E largely determine both the local concentration of current in high density strips and the local magnitude of the field aligned current. As grad $\mathbb{N}$ at 100-130 $\mathrm{km}$ altitude is determined by the pattern of precipitating (i.e., ionizing) particles a cause and effect relationship exists between the precipitation and the field aligned current. The field aligned current is not, however, identified directly with the precipitating flux when the grad E dependence is taken into account. The large scale, net distribution of field aligned currents that results from merging the pattern of convection with maximum concentrations of ionization is consistent with associating the net sheet currents with the auroral belt regions of electrojet reversals where the polar cap convective flow divides into eastward and westward flow.

The required closure of the electrojet-field aligned circuits in the magnetospheric equatorial plane is consistent with gradient and curvature particle drifts that would produce observed asymmetric ring current effects. However, a more complete understanding of the magnetospheric closure and current generating processes in the magnetosphere is needed as well as an identification of particle populations giving the net current. 


\section{Acknowledgments}

The barium release experiments at the Pin-Main DEWline Station were made possible through the cooperation of cognizant offices of the U.S. Air Force, the Canadian Air Force, and the National Research Council of Canada. These agencies, the DEW System contractor (the Federal Electric Corporation), and the rocket services contractor (the Thiokol Chemical Corporation) made this seemingly difficult project a relatively simple operation which was completely successful. We particularly thank our GSFC co-workers that operated cameras at the three stations and Mrs. Mary Miller for her skilled efforts in reducing the photographic plates and programming the analyses. 


\section{References}

Aggson, T. L., Probe measurements of electric fields in space, Atmospheric Emissions, ed. by B. M. McCormac and A. Omholt, Van Nostrand Reinhold Co., N.Y., pp. 305-316, 1969.

Akasofu, S.-I., A model current system for the magnetospheric substorm, Particles and Fields in the Magnetosphere, ed. by B. M. McCormac, D. Reide1 Pub1. Co., pp. 34-45, 1970.

Axford, W. I., and C. O. Hines, A unifying theory of high-1atitude geophysical phenomena and geomagnetic storms, Can. J. Phys., 39, 1433-1463, 1961.

Baker, K. D., W. Pfister, and J. C. Ulwick, Change densities and temperatures measured in active auroras, Space Research VII, North-Holland Pub1. Co., Amsterdam, pp. 665-673, 1967.

Berthelier, J. J. and D. J. Sturges, Simultaneous measurements of electron density and temperature in the northern auroral zone, Planet. Space Sci., $15,1049-1054,1967$.

Burrows, K., J. D. Stolarik, and J. P. Heppner, Measurements of the magnetic fields associated with visual aurora, submitted to Planet. Space Sci., Preprint, 1970.

Cahil1, L. J., Magnetosphere inflation during four magnetic storms in 1965, J. Geophys. Res., 75, 3778-3788, 1970.

Cole, K. D., Motions of the aurora and radio-aurora and their relationships to ionospheric currents, Planet. Space Sci., 10, 129-163, 1963.

Coleman, P. J. and McPherron, R. L., Fluctuations in the distant geomagnetic field during substorms: ATS-1, Particles and Fields in the Magnetosphere, ed. by B. M. McCormac, D. Reide1 PubI. Co., pp. 171-194, 1970.

Cummings, W. D., Asymmetric ring currents and the low latitude disturbance daily variation, J. Geophys. Res., 71, 4495-4503, 1966. 
Dalgarno, A., I. D. Latimer, and J. W. McConkey, Corpuscular bombardment and $\mathrm{N}_{2}+$ radiation, Planet. Space Sci., 13, 1008-1009, 1965.

Eather, R. H., Latitudinal distribution of auroral and airglow emissions: The "soft" auroral zone, J. Geophys. Res., 74, 153-158, 1969.

Fejer, J. A., The effects of energetic trapped particles on magnetospheric motions and ionospheric currents, Can. J. Phys., 39, 1409-1417, 1961. Föppl, H., G. Haerende1, L. Haser, R. Lüst, F. Melzner, B. Meyer, N. Neuss, H. H. Rabben, E. Rieger, J. Stöcker, and W. Stoffregen, Preliminary results of electric field measurements in the auroral zone, J. Geophys. Res. 73, 21-26, 1968.

Gurnett, D. A., Satellite measurements of D. C. electric fields in the ionosphere; Particles and Fields in the Magnetosphere, ed. by B. M. McCormac, D. Reidel Pub1. Co., pp. 239-246, 1970.

Haerende1, G. R., R. Lüst, and E. Rieger, Motion of artificial ion clouds in the upper atmosphere, Planet. Space Sci., 15, 1-18, 1967. Haerende1, G., R. Lüst, E. Rieger, and H. Völk, Highly irregular artificial plasma clouds in the auroral zone, Atmospheric Emissions, ed. by B. M. McCormac and A. Omholt, pp. 293-303, Van Nostrand Reinhold Co., N.Y., 1969. HaerendeI, G. and R. Lüst, Electric fields in the ionosphere and magnetosphere, Particles and Fields in the Magnetosphere, ed, by B. M. McCormac, D. Reide1 Pub1. Co., pp. 213-228, 1970.

Heikkila, W. J. and J. David Winningham, The soft particle spectrometer, (Abstract) Trans. AGU, 5I, No. 4, p. 375, 1970.

Heppner, J. P., A study of relationships between the aurora borealis and the geomagnetic disturbances caused by electric curkents in the ionosphere, printed as Canadian DRB Report No. DR 135, 1958; Thesis, Calif. Inst. of Tech., 1954. 
Heppner, J. P., High latitude magnetic disturbances, Aurora and Airglow, ed. by B. M. McCormac, pp. 75-92, Reinhold Publishing Co., N. Y., $1967 a$.

Heppner, J. P., Recent measurements of the magnetic field in the outer magnetosphere and boundary regions, Space Sci. Reviews, I, 166-190, $1967 \mathrm{~b}$. Heppner, J. P., M. Sugiura, T. L. Skillman, B. G. Ledley and M. Campbe11, OGO-A magnetic field observations, J. Geophys. Res., 72, 5417-5471, 1967. Heppner, J. P., Magnetospheric convection patterns inferred from high latitude activity, Atmospheric Emissions, ed. by B. M. McCormac and A. Onholt, pp. 251-266, Van Nostrand Reinhold Co., N. Y., 1969. Heppner, J. P., J. D. Stolarik, and E. M. Wescott, Field aligned continuity of Hall current electrojets and other consequences of density gradients in the auroral ionosphere, The Radiating Atmosphere, ed. by B. M. McCormac, D. Reidel Pub1. Co., (to be published) 1971. Jespersen, M., B. Iandmark, and K. Måseide, Comparison of auroral Iight emission and electron density, J. Atmosph. Terr. Phy., 31, 1251-1257, 1969. Keneshea, T. J., R. S. Narcisi, and W. Swider, Jr., Diurnal models of the E region, J. Geophys. Res., 75, 845-854, 1970.

Lerfald, G. M. and C. G. Little, D-region electron temperatures at the northern aurora1 zone, Radio Science, 5, 1017-1028, 1970.

Maynard, N. C. and J. P. Heppner, Variations in electric fields from polar orbiting satellites, Particles and Fields in the Magnetosphere, ed. by B. M. McCormac, D. Reide1 Pub1. Co., pp. 247-253, 1970. McNamara, A. G., Rocket measurements of plasma densities and temperatures in visual aurora, Can. J. Phys., 47, 1913-1927, 1969. Mead, G. D., Deformation of the geomagnetic field by the solar wind, J. Geophys. Res., 69, 1181-1195, 1964. 
Nagata, T. and S. Kokubun, Polar magnetic storms, with special reference to relation between geomagnetic disturbances in the northern and southern auroral zones, Rept. Ionosph. Res., Japan, 14, 273-290, 1960. Nishida, A, S. Kokubun, and N. Iwasaki, Annual variations in the magnetospheric configuration, and its influence on the polar magnetic field, Rept. Ionosph, Res., Japan, 20, 73-78, 1966.

Omholt, A., Physical composition of aurora, Ann. Geophys., 22, 217-223, 1966. Penndorf, R., The average ionospheric conditions over the Antarctic, Geomagnetism and Aeronomy, Antarctic Research Series 4, American Geophysical Union, pp. 1-45, 1965. Reddy, C. A., Physical significance of the $E_{s}$ parameters $f_{b} E_{s}$, $f E_{s}$, and $\mathrm{f}_{\mathrm{O}} \mathrm{E}_{\mathrm{S}}$, J. Geophys. Res.; 73, 5627-5647, 1968.

Reddy, C. A., M. Mukunda Rao, and S. Matsushita, Rocket observations of electron densities in the night-time auroral E-region at Fort Churchill, Planet. Space Sci., 17, 617-628, 1969.

Sharp, R. D., D. I. Garr, and R. G. Johnson, Satellite observations of the average properties of auroral particle precipitations: Latitudinal variations, J. Geophys. Res., 74, 4618-4630, 1969.

Silsbee, H. C. and E. H. Vestine, Geomagnetic bays, their frequency and current systems, Terr. Magn. and Atm. Elec., 47, 195-208, 1942.

Sugiura, M., T. I. Skillman, B. G. Ledley, and J. P. Heppner, Magnetic field observations in "high $\beta$ regions of the magnetosphere, Particles and Fields in the Magnetosphere, ed. by B. M. McCormac, D. Reidel Pub1. Co., pp. $165-170,1970$

Taylor, H. E., and E. W. Hones, Jr., Adiabatic motion of auroral particles in a model of the electric and magnetic fields surrounding the earth, J. Geophys. Res., 70, 3605-3628, 1965. 
Unwin, R. S. and F. B. Knox, The morphology of the v.h.f. radio aurora at sunspot maximum, J. Atmosph. Terr. Phys., 30, 25-46, 1968.

Vasyliunas, V. M., Mathematical models of magnetospheric convection and its coupling to the ionosphere, Particles and Fields in the Magnetosphere, . ed. by B. M. McCormac, D. Reide1 Pub1. Co., pp. 60-71, 1970. Wescott, E. M., J. D. Stolarik, and J. P. Heppner, Electric fields in the vicinity of auroral forms from motions of barium vapor releases, J. Geophys. Res., 74, 3469-3487, 1969.

Wescott, E. M., J. D. Stolarik, and J. P. Heppner, Auroral and polar cap electric fields from barium releases, Particles and Fields in the Magnetosphere, ed. by B. M. McCormac, D. Reide1 Pub1. Co., pp. 229-238, 1970. Williams, D. J. and G. D. Mead, Nightside magnetosphere configuration as obtained from trapped electrons at 1100 kilometers, J. Geophys. Res., 70, 3017-3029, 1965.

Winningham, J. D., (Presentation) Aurora and Airglow, 1970; Advanced Study Institute, Kingston, Ont.,.. Ganada, Aug. 1970. 
Figure Captions

Figure 1. (a), (b), and (c): model vector relationships for ionospheric sheet currents. (d): typical observed relationship between $\underline{V}($ or $\mathrm{E})$ and $\Delta \stackrel{\mathrm{H}}{\sim}$.

Figure 2. Illustration of the closest approach of aurora to the release region throughout the period of observations. Dashed line outlines all-sky camera coverage. $\Lambda=$ invariant latitude. Release points are labelled with the time of release: Release 1 by hr., min., sec., and Releases 2, 3, and 4 by min. and sec.

Figure 3. Tracks of four $\mathrm{Ba}^{+}$clouds from Flight I, projected along magnetic field lines to a common plane at an altitude of $100 \mathrm{~km}$. Triangulated locations at $20 \mathrm{sec}$ intervals (dots) are given with UT, minutes and seconds, noted at one minute intervals. Coordinates are geographic with invariant latitude, ${ }^{-} \Lambda$, superimposed (dashed lines).

Figure 4. Horizontal magnetic disturbance vectors from high latitude observatories at $13^{\mathrm{h}} 19^{\mathrm{m}} \mathrm{UT}$, March 7 , 1969. Disturbance in the $Z$ component is given in gammas at the base of each vector. Tracks of Flight $1 \mathrm{Ba}^{+}$clouds appear as short solid lines. Coordinates are geomagnetic latitude and magnetic time.

Figure 5. Electric field measurements and polar cap magnetic disturbance vs. time for Flight 1 . See text and-Figure 1 for definition of angles $\Psi_{E}$ and $\Psi_{\Delta H}$.

Figure 6. Tracks of four $\mathrm{Ba}^{+}$clouds from Flight 2, projected along magnetic field lines to a common plane at an altitude of $100 \mathrm{~km}$. Points connected by lines are instantaneous positions of major striated segments of the same cloud. 
Figure 7. Horizontal magnetic disturbance vectors from high latitude observatories at $03^{h} 25^{\mathrm{m}}$ UT, March 8 , 1969. $\Delta \mathrm{Z}$ is given in gammas at the base of each vector. Short solid lines are the tracks of Flight $2 \mathrm{Ba}^{+}$clouds. Coordinates are geomagnetic latitude and magnetic time.

Figure 8. Electric field measurements and the polar cap magnetic disturbance vs. time for Flight 2 .

Figure 9. Tracks of principal ray segments of four Bat clouds from Flight 3 , projected along magnetic field lines to a common plane at an altitude of $100 \mathrm{~km}$.

Figure 10. Horizontal magnetic disturbance vectors from high latitude observatories at $03^{\mathrm{h}} 36^{\mathrm{m}}$ UT, March 9 , 1969. $\Delta \mathrm{z}$ is given in gammas at the base of each vector. Short solid lines are the tracks of Flight $3 \mathrm{Ba}^{+}$ciouds. Coordinates are geomagnetic latitude and magnetic time.

Figure 11. Electric field measurements and the polar cap magnetic disturbance vs. time for Flight 3 .

Figure 12. To illustrate Hall current continuity in the presence of plasma density discontinuities (or gradients) (see text).

Figure 13. Idealized illustration of continuity problem for a strip of enhanced plasma density (e.g., an auroral arc) aligned along east-west equipotentials of the convective field. View of horizontal plane between 100 and $130 \mathrm{~km} . \quad \mathbb{N}=\mathbb{N}_{e}=\mathbb{N}_{i}=$ electrically neutral plasma density. 
Figure 14. Schematic illustrations of: (a) a distribution of Hall current electrojets terminated in the ionosphere by currents along magnetic field lines, and (b) the net distribution of electrojet terminations resulting in "sheet" configurations for the net field aligned current. $\Delta \mathrm{H}$ and $\Delta \mathrm{Y}$ vectors indicate, respectively, polar cap and middle latitude magnetic disturbances attributed to the sheet currents Open and filled circles, respectively, indicate current "out of" and "into" the ionosphere along magnetic field lines.

Figure 15. To illustrate the change in distribution of ionospheric terminations of field aligned currents in going from a case, (a), where the entire auroral belt is uniformly conducting to a case, (b), where high conductivity exists only in strips parallel to the convection. Continuous lines form the idealized convective pattern. Terminated segments in (b) represent auroral electrojets. $N=$ plasma density at 100-130 km altitude. Open and filled circles, respectively, indicate current "out of" and "into" the ionosphere along magnetic field lines.

Figure 16. Magnetospheric distribution of the net field aligned current and its continuation in the equatorial plane. 
(a), (b), (c) = IDEALIZED IONOSPHERE CURRENT MODELS

(a) $i_{h} \gg i_{p}$
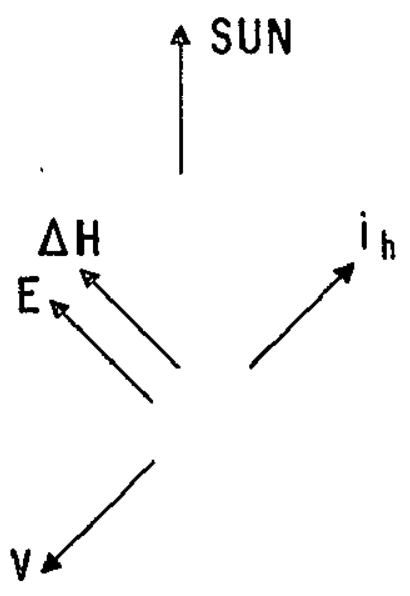

$\Psi_{\Delta H} \doteq \Psi_{E}$ (b) $i_{h} \ll i_{p}$<smiles>C[AsH3]</smiles>

(c) $i_{h} \doteq i_{p}$
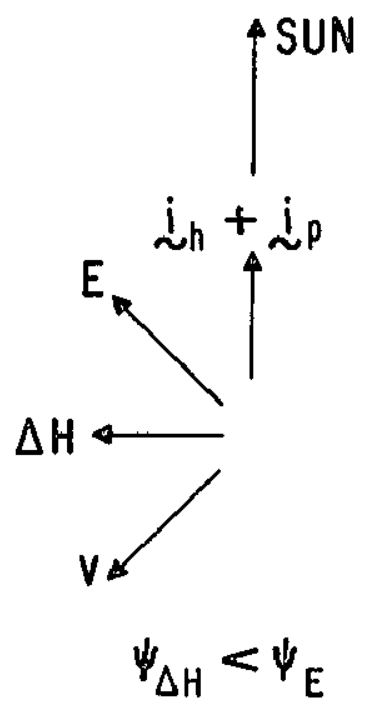

Definition of $\psi$

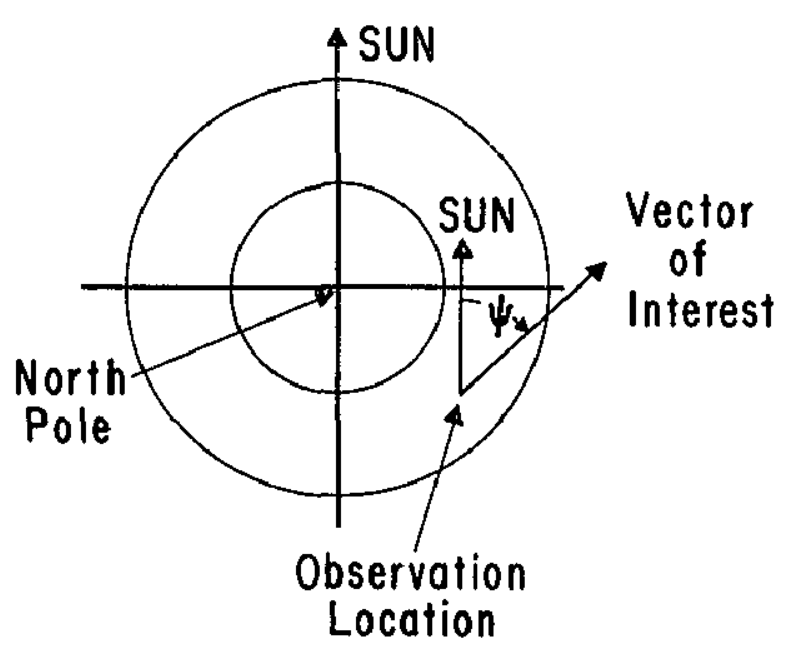

(d) Observed Relationships.
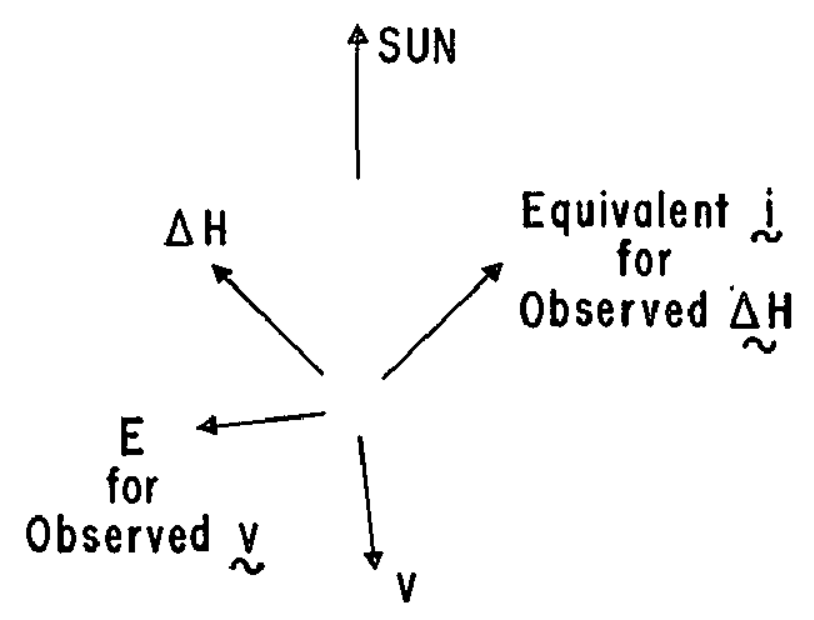

$$
\psi_{\Delta H}>\psi_{E}
$$

FIGURE I 


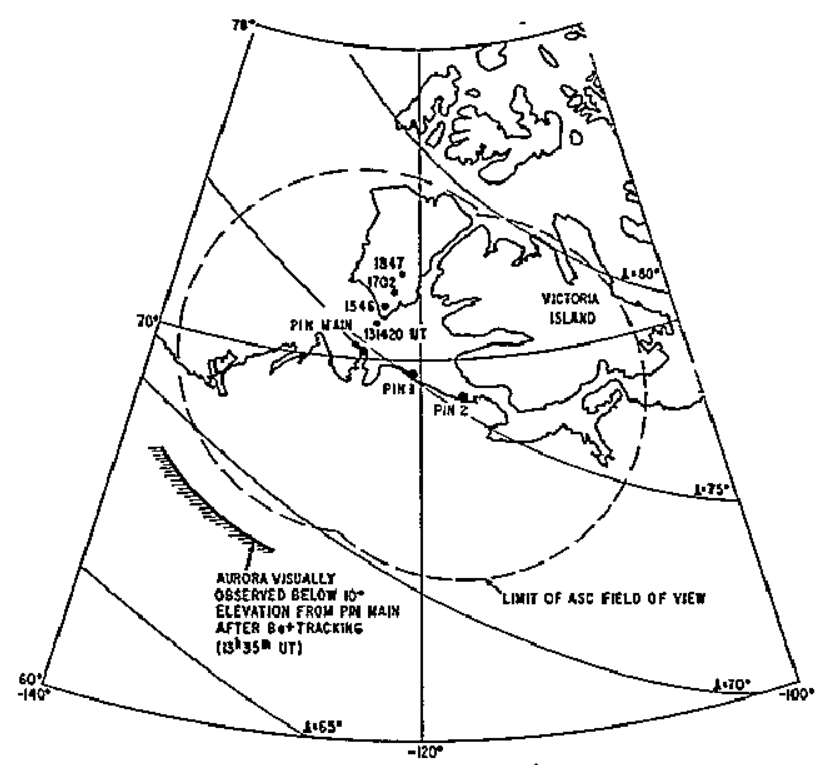

FLIGHT\#! MARCH $T_{2}$, $1969 T_{0}=13^{h} 12^{m_{0}} 0^{S}$ UT
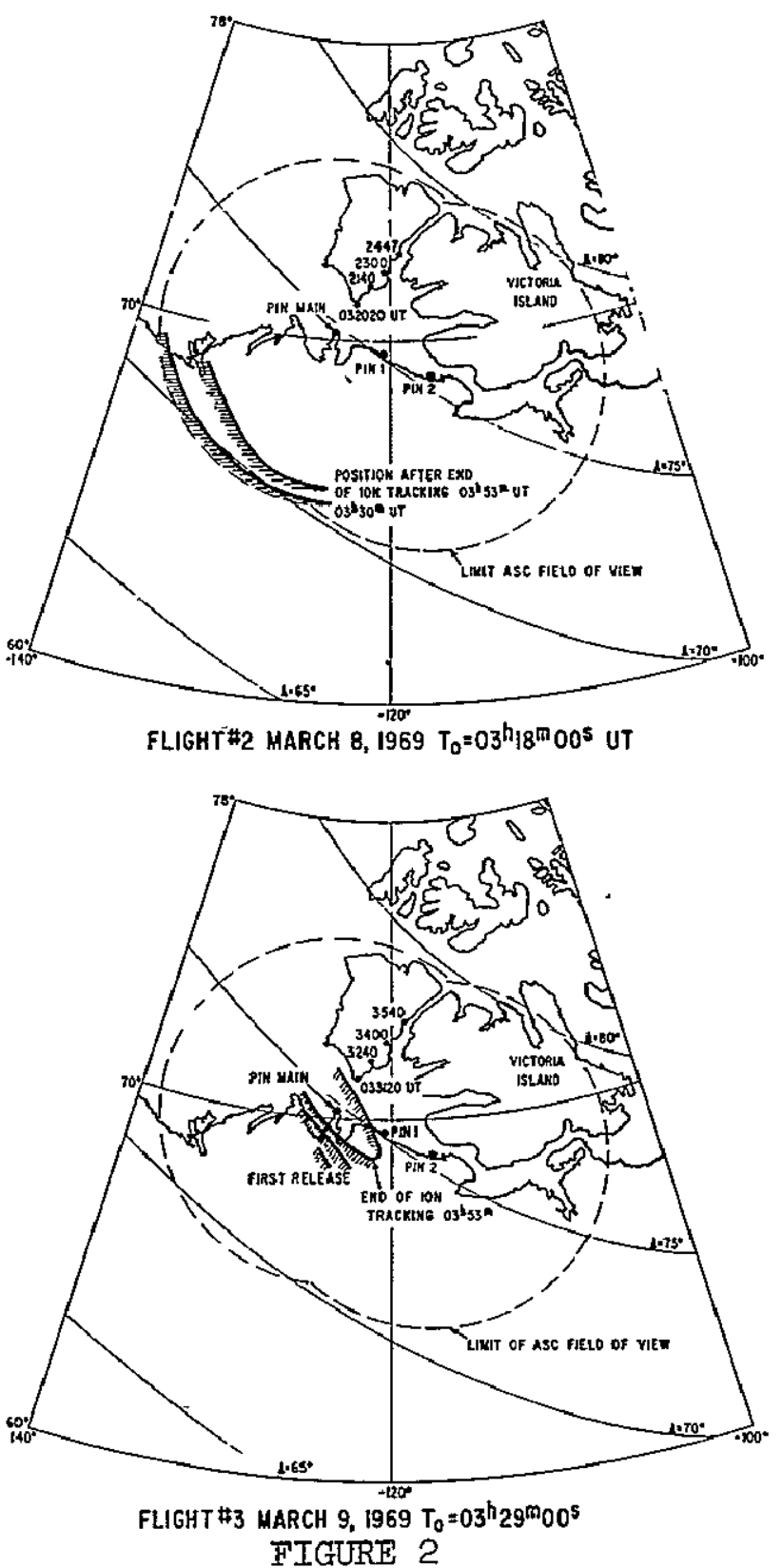


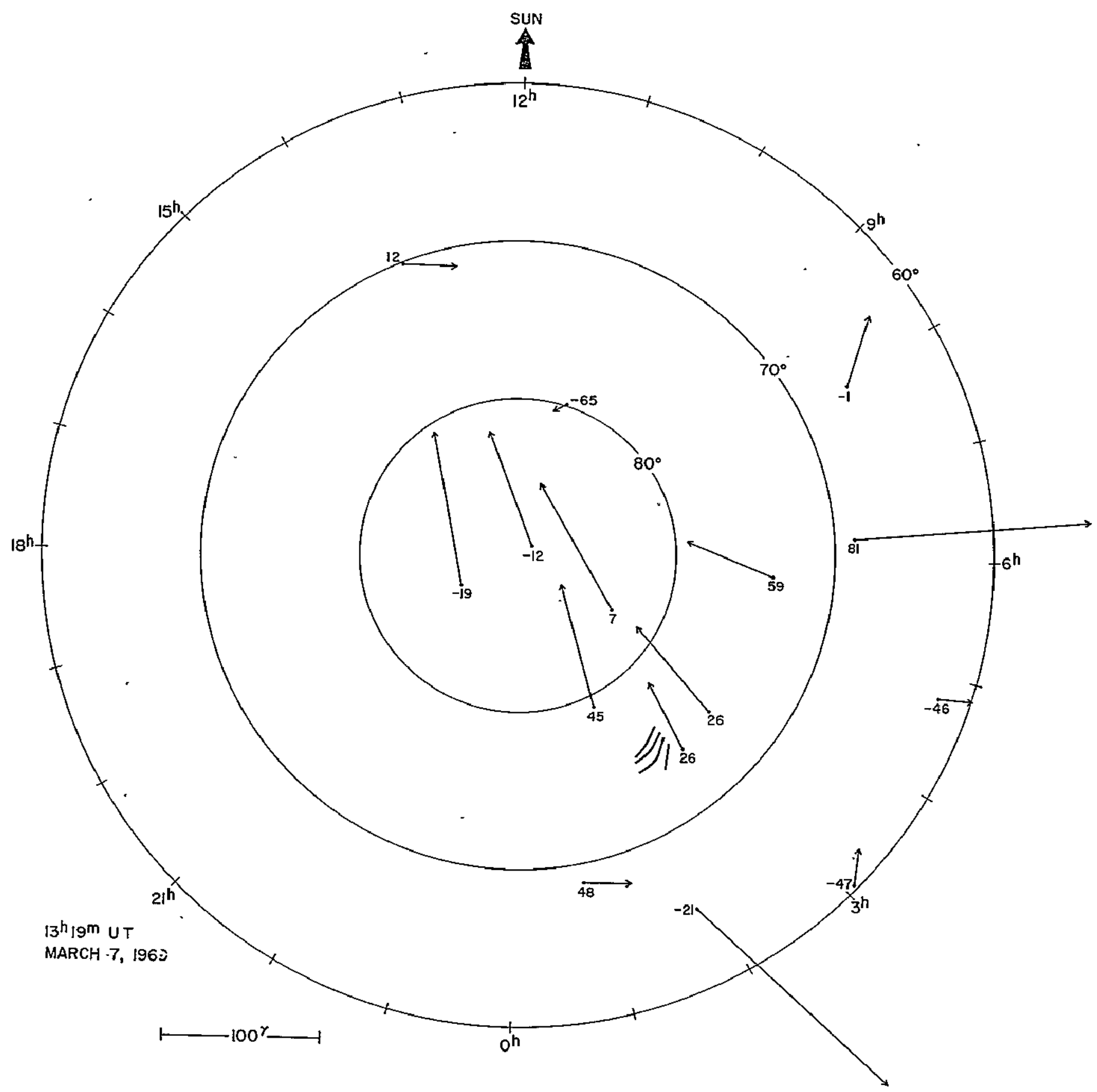

FIGURE 4 


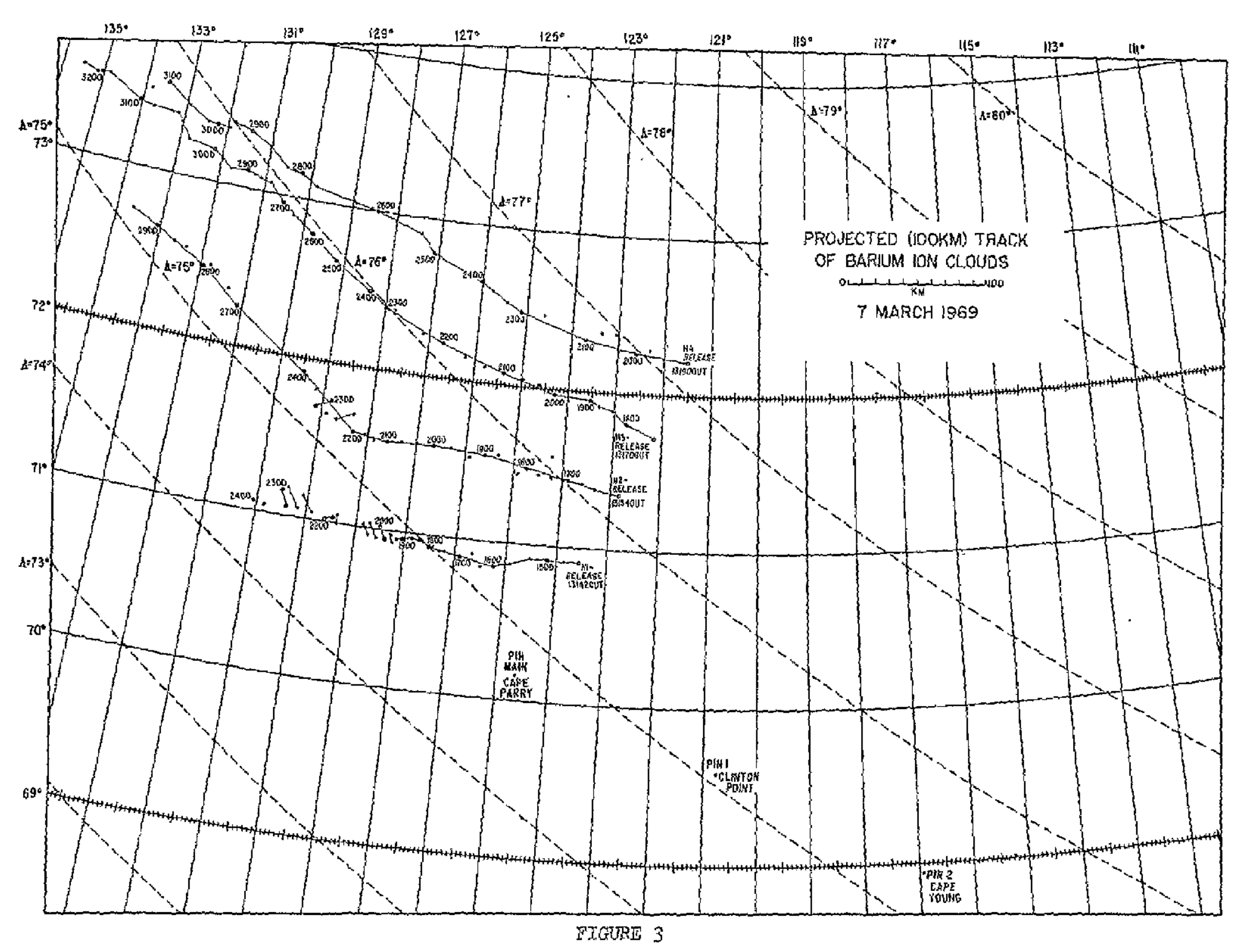



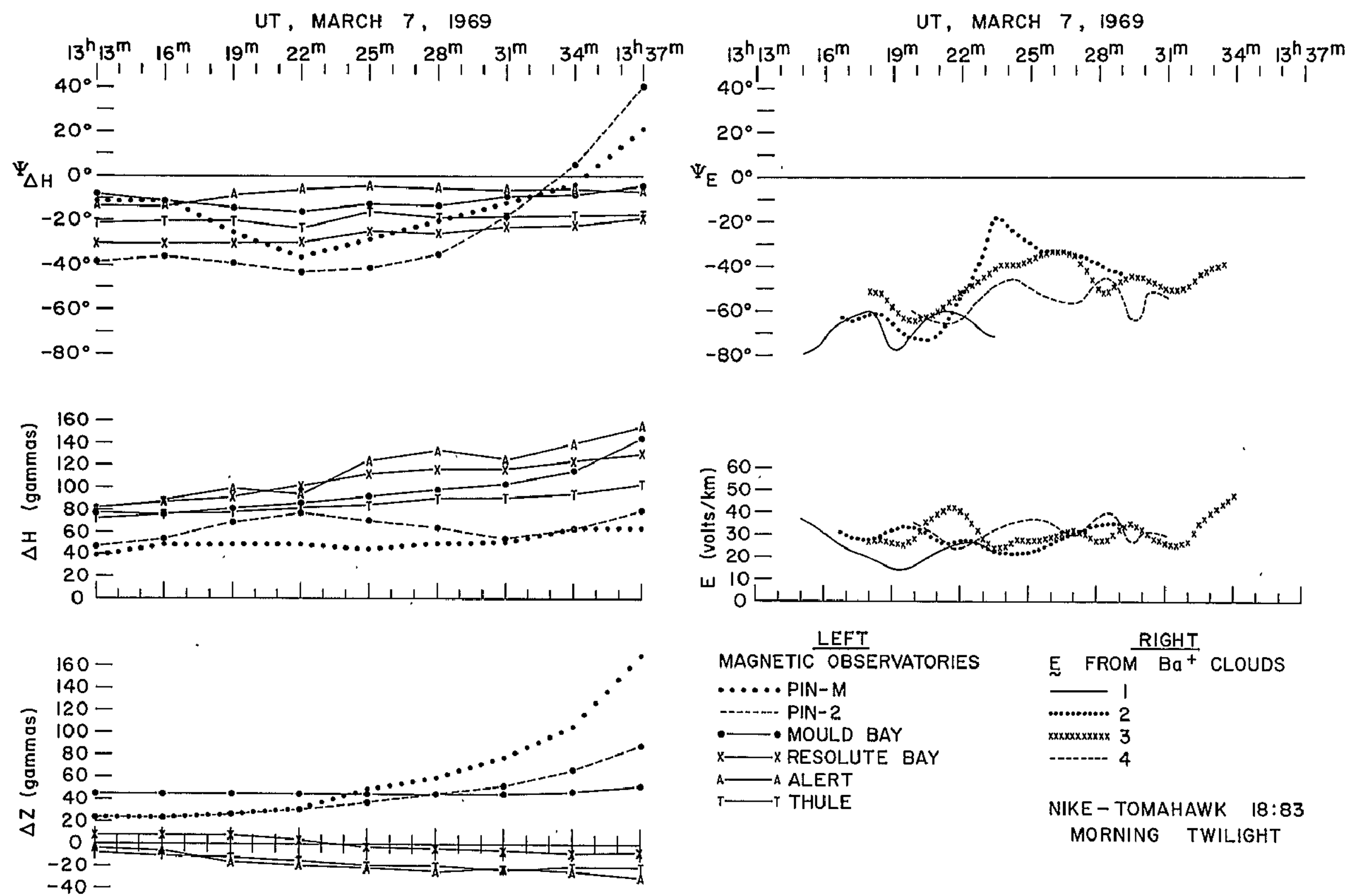

FIGURE, 5 


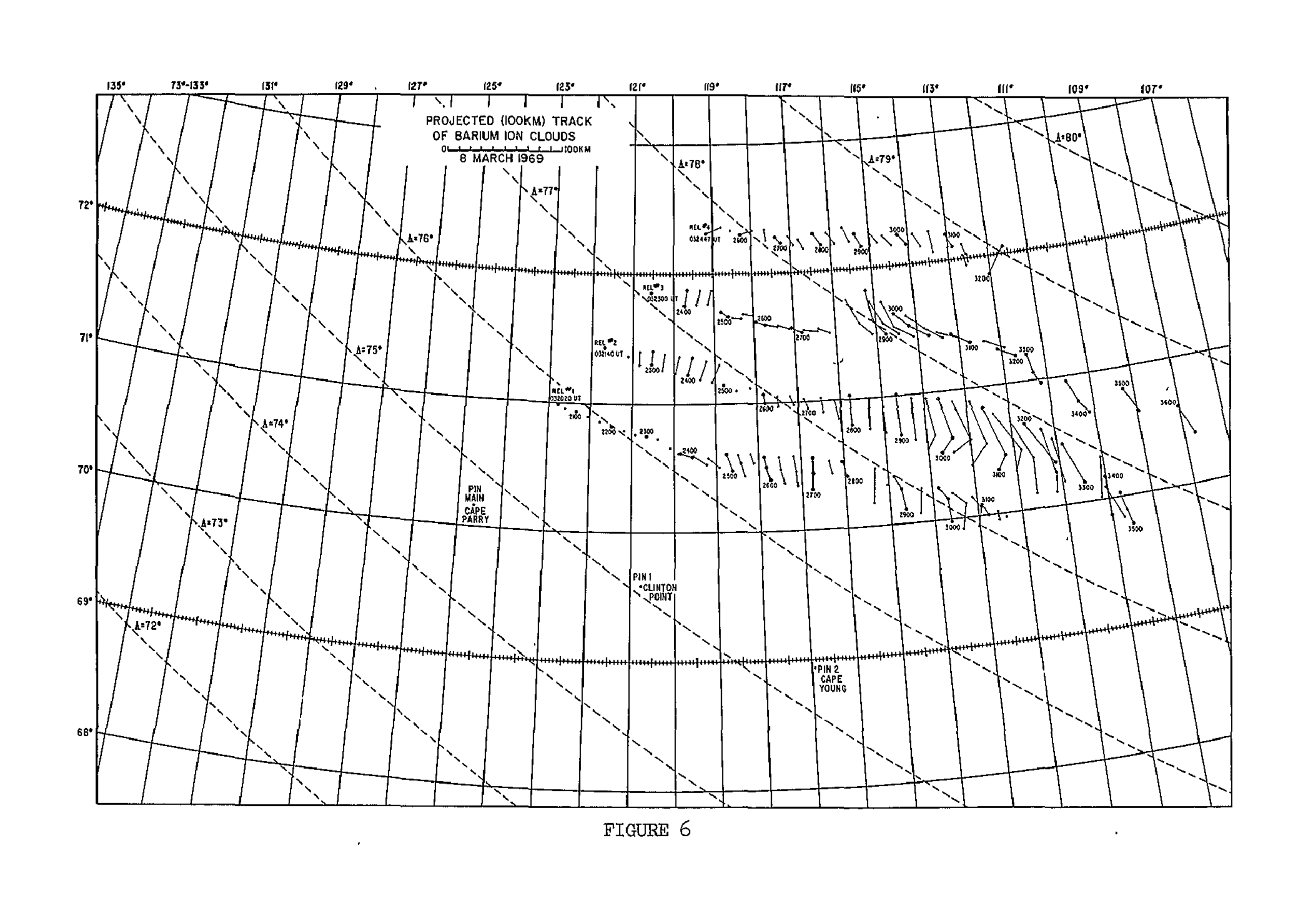



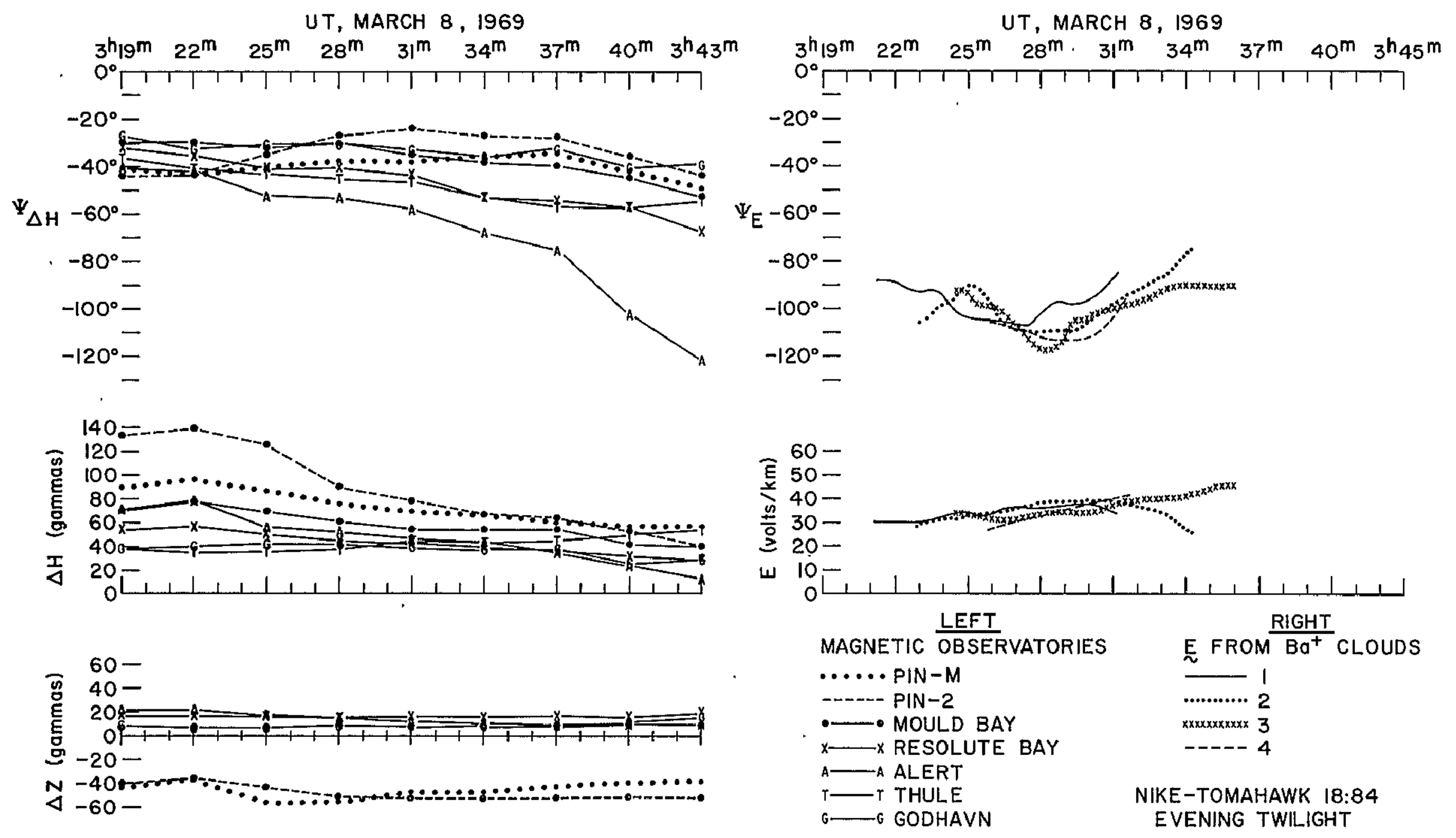

FIGURE 8 


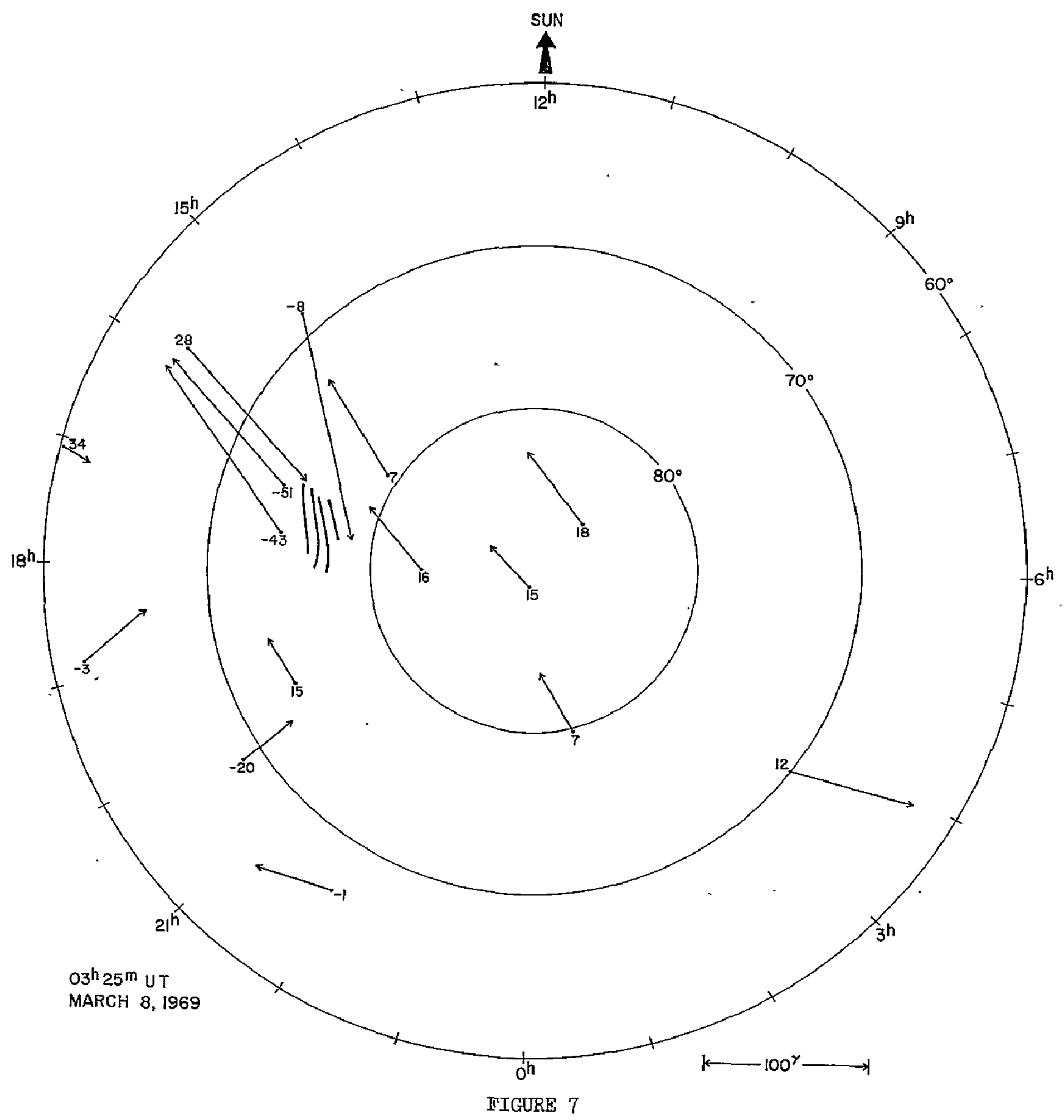




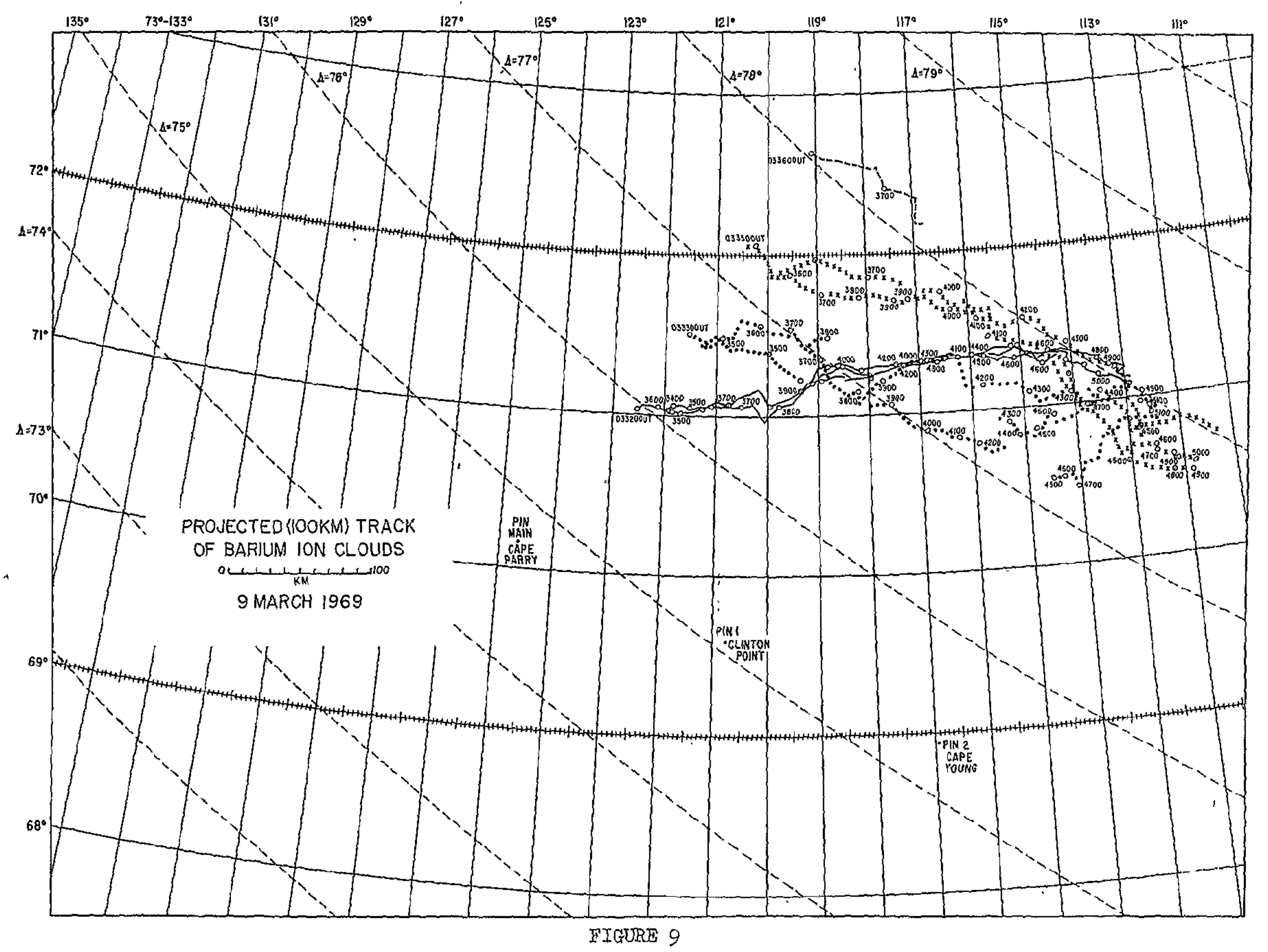




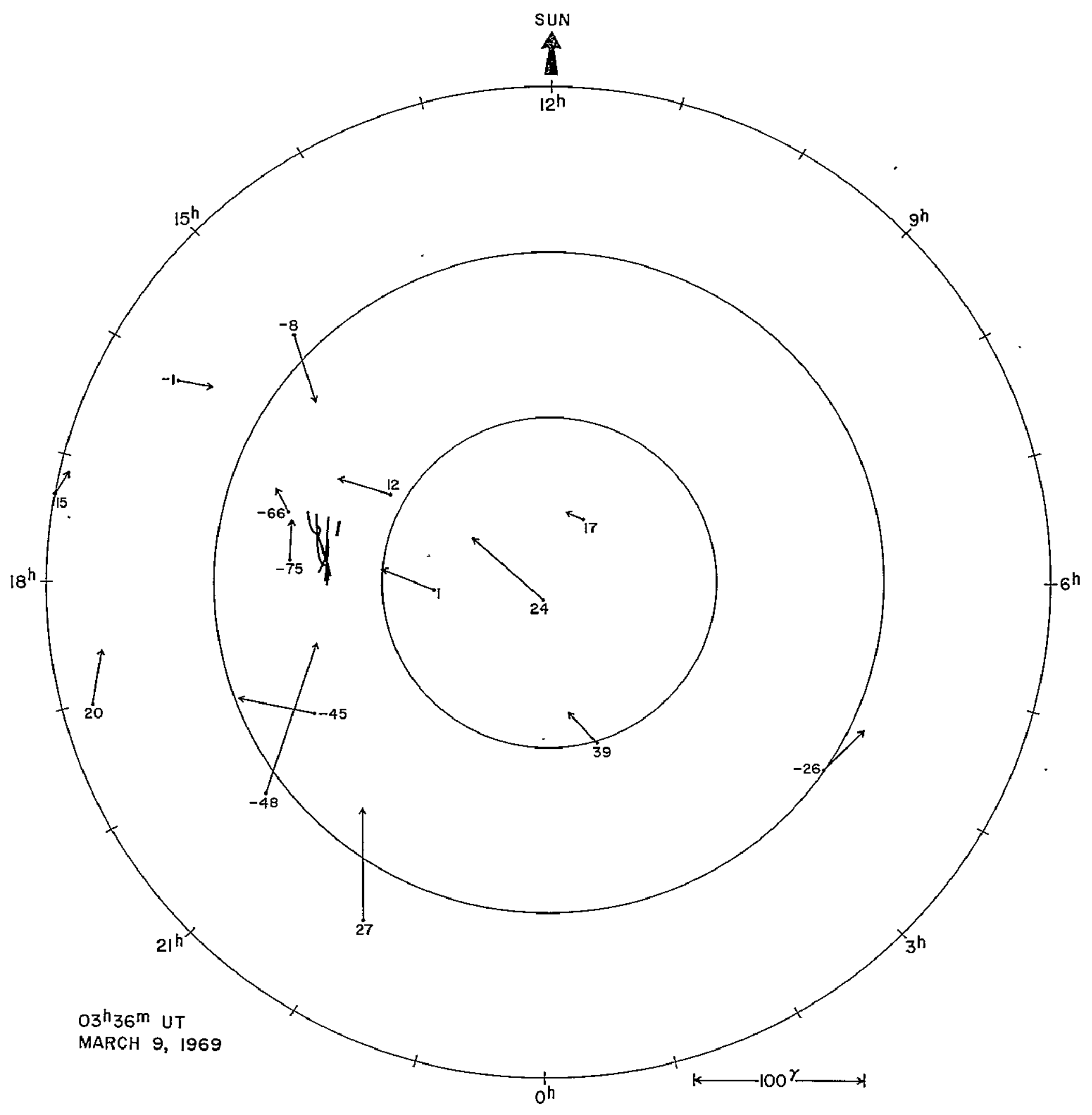

FIGURE 10 


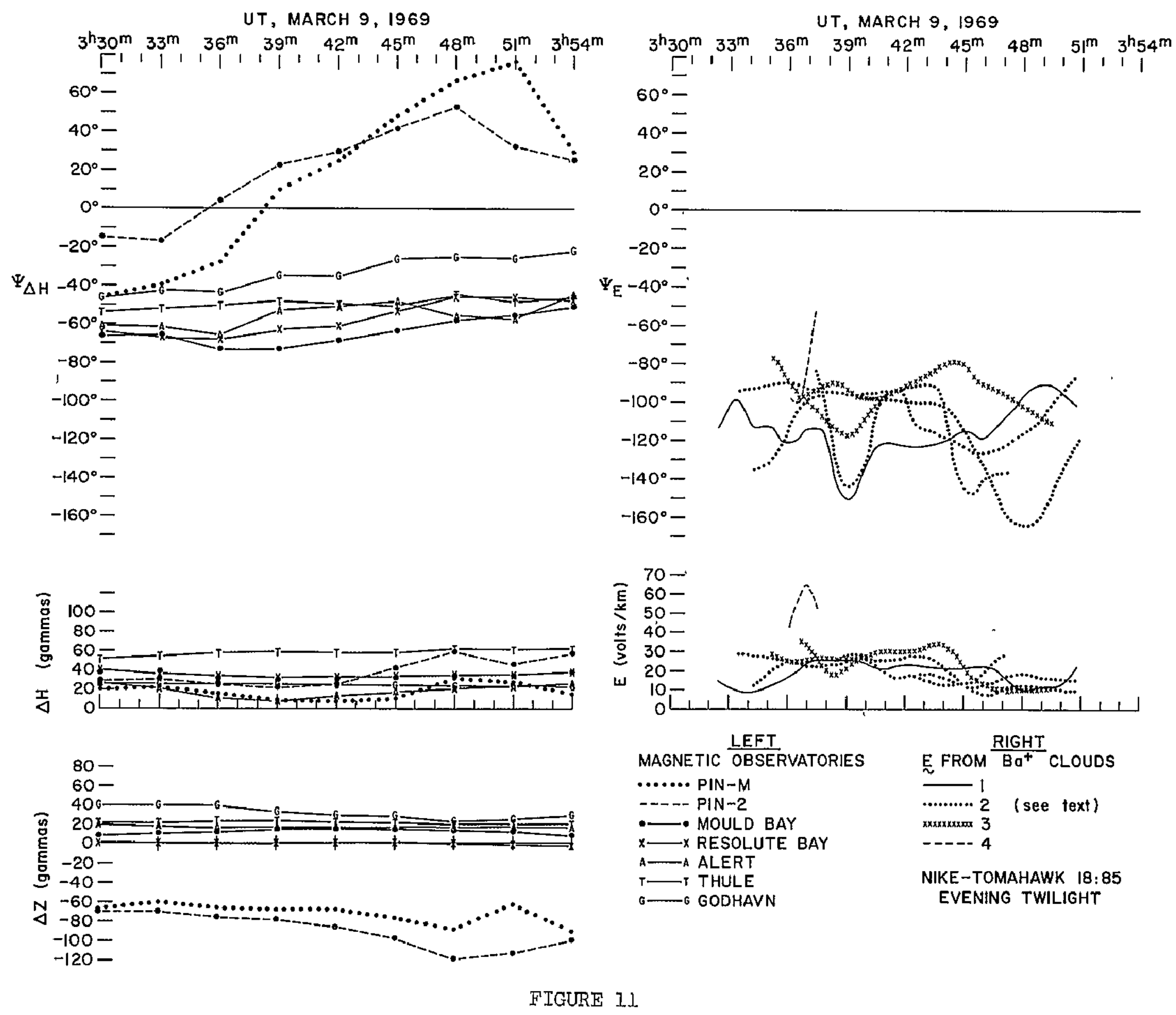




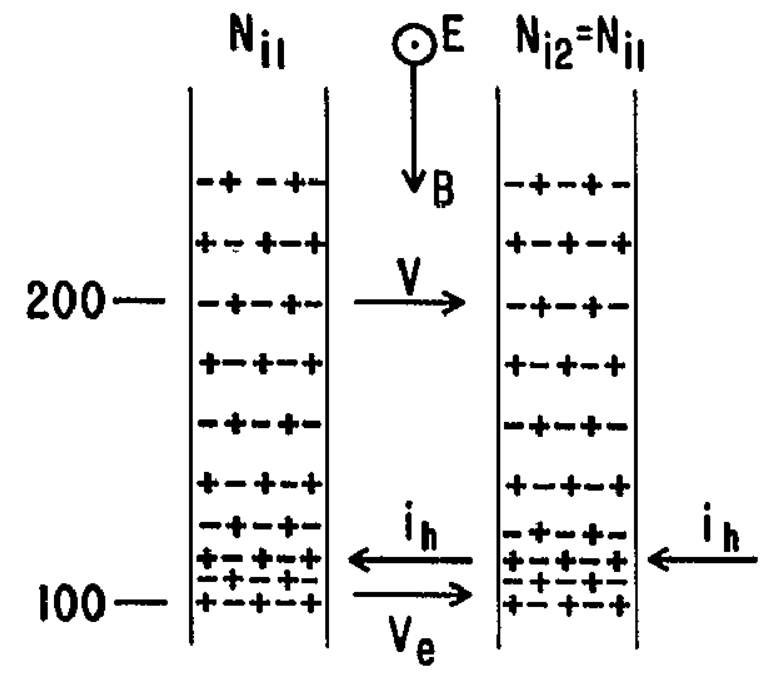

0

A. UNIFORM IONOSPHERE
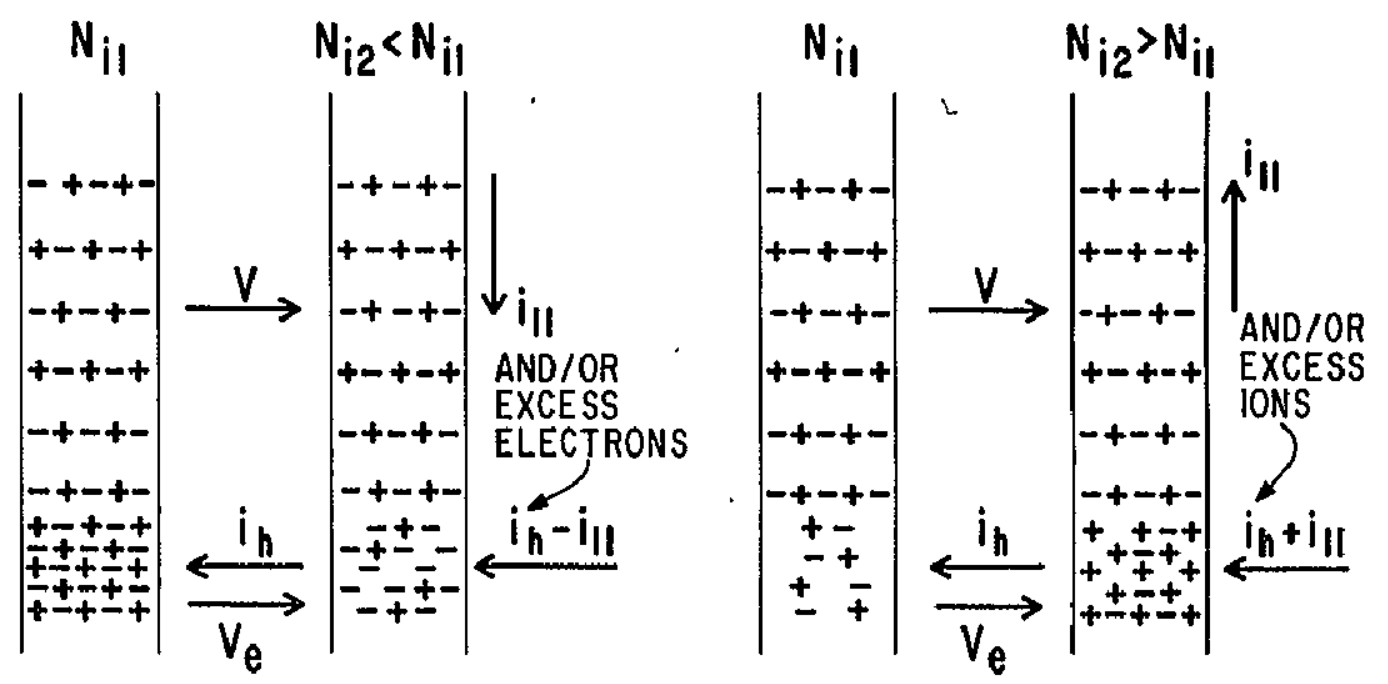

B. HORIZONTAL DISCONTINUITY IN PLASMA DENSITY AT ALTITUDES 100-130 KM. FLUX TUBE MOTION FROM HIGH TO LOW DENSITY
C. HORIZONTAL DISCONTINUITY IN PLASMA DENSITY AT ALTITUDES 100-130 KM. FLUX TUBE MOTION FROM LOW TO HIGH DENSITY 
CONTINUITY OF HALL CURRENT

HORIZONTAL STRIP OF ENHANCED PLASMA DENSITY AT ALTITUDES 100-130 KM
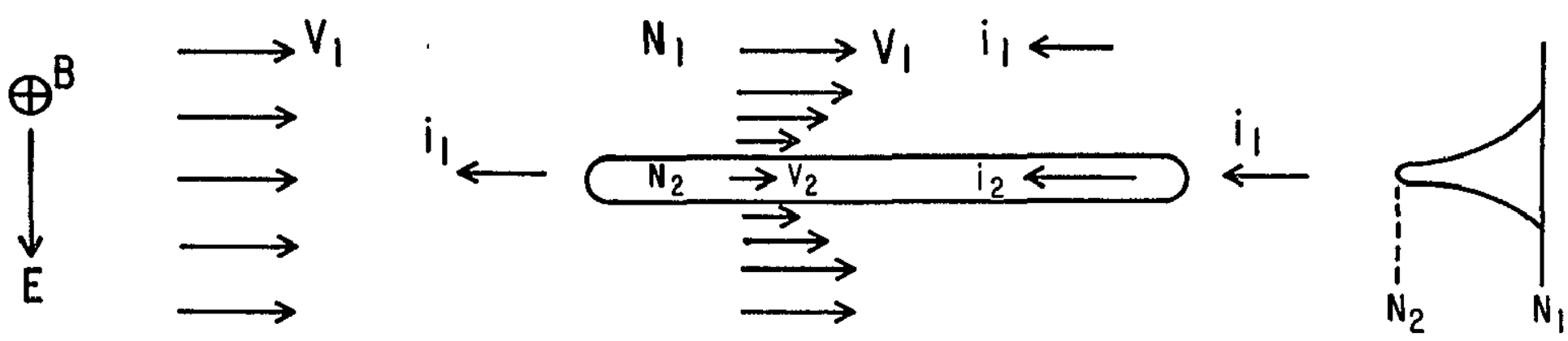

$i_{1} \propto N_{1} v_{1}$

$\mathrm{i}_{2} \propto \mathrm{N}_{2} \mathrm{~V}_{2}$ $N_{2}=K N_{1}$

$V_{1}=C V_{2}$

$k>1$

$C>1$

N-S DENSITY DISTRIBUTION

CASE (I) : $i_{/ /}=0$

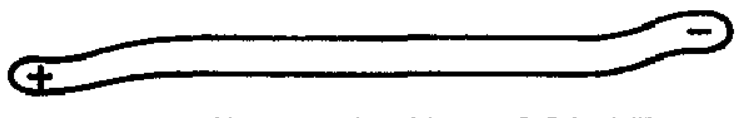

$N_{1} V_{1}=N_{2} V_{2}=C O N S T$.

$C=K>1$

(a) DIRECT RELATIONSHIP $N \propto \frac{1}{V}$ BETWEEN

$\checkmark$ (FROM MAGNETOSPHERE E FIELD) AND

N (PLASMA DENSITY AT 100-130 KM)

(b) $i_{2}=i_{1}$ : CURRENT IS NOT ENHANCED IN HIGH DENSITY STRIP
CASE (2): $i_{\|} \neq 0$

(A) "SMALL" $i_{/ / \text {IF } \mathrm{C} \rightarrow \mathrm{K}}$

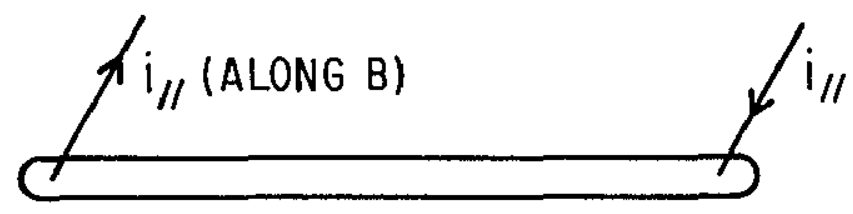

(B) "LARGE" $i / /$ IF $K \gg C$

REGARDLESS OF MAGNITUDE OF $K>1$ (SAME PROBLEM AS CASE(I)) (a) AVOIDS DIRECT RELATIONSHIP BETWEEN V AND N.

(b) IMPLIES $\left(N_{2}-N_{1}\right)$ RELATED TO PARTICLES AVAILABLE FROM MAGNETOSPHERE.

(c) $K \gg C>\mid$ AGREES WITH VARIOUS TYPES OF OBSERVATIONS.

(d) $i_{2}=i_{1}+i_{/ /}$: CURRENT IS ENHANCED IN HIGH DENSITY STRIP 

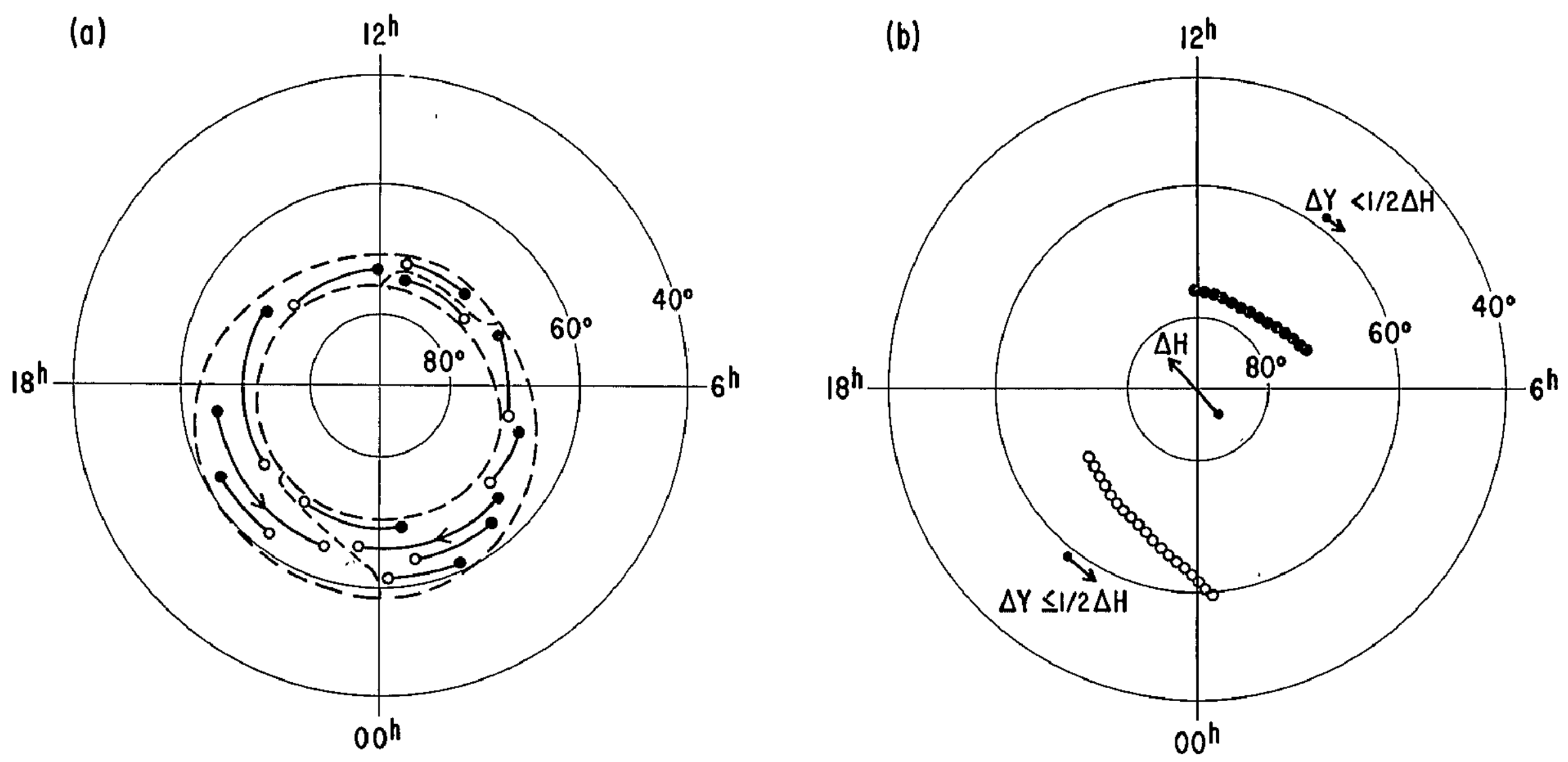

FIGURE 14 


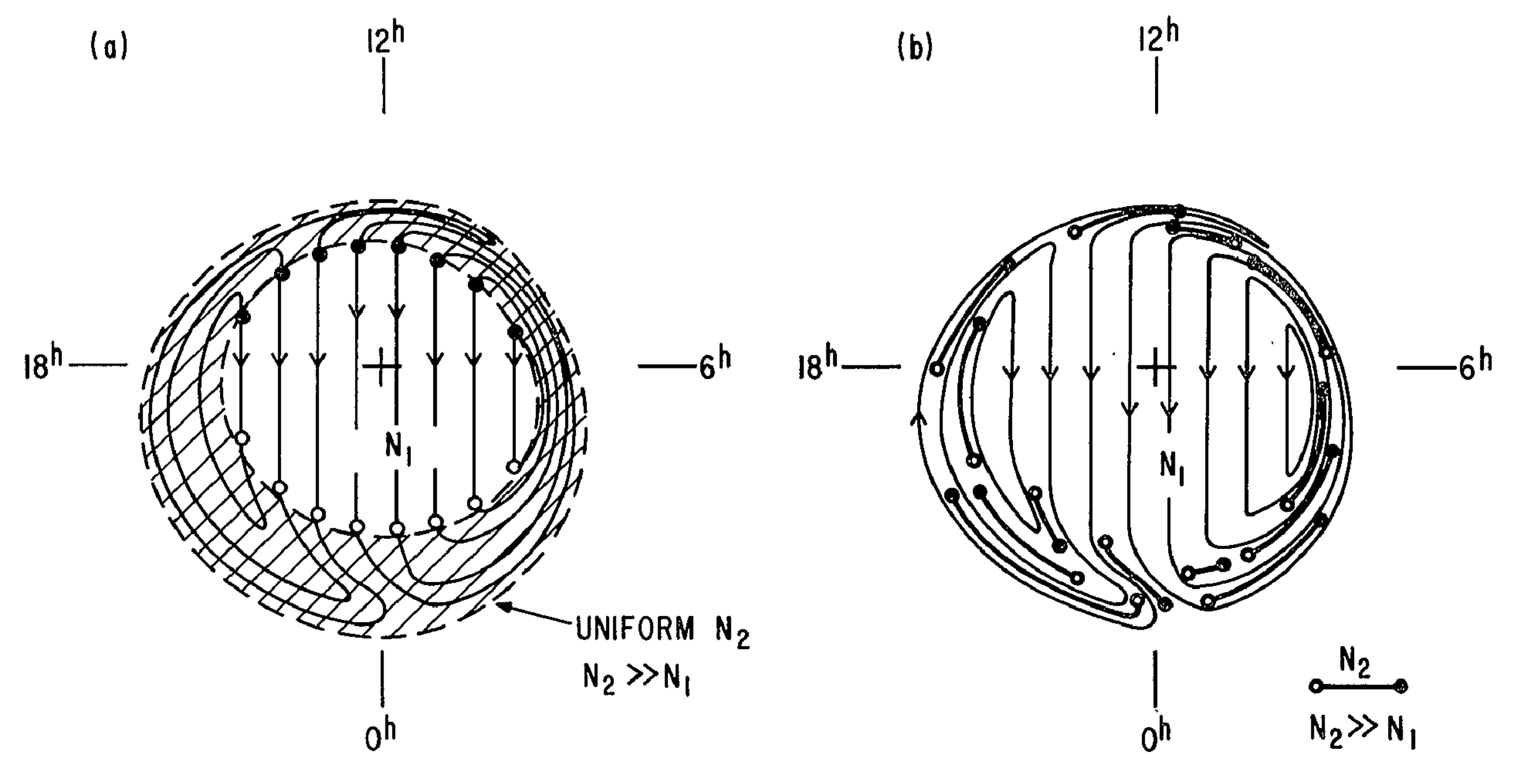




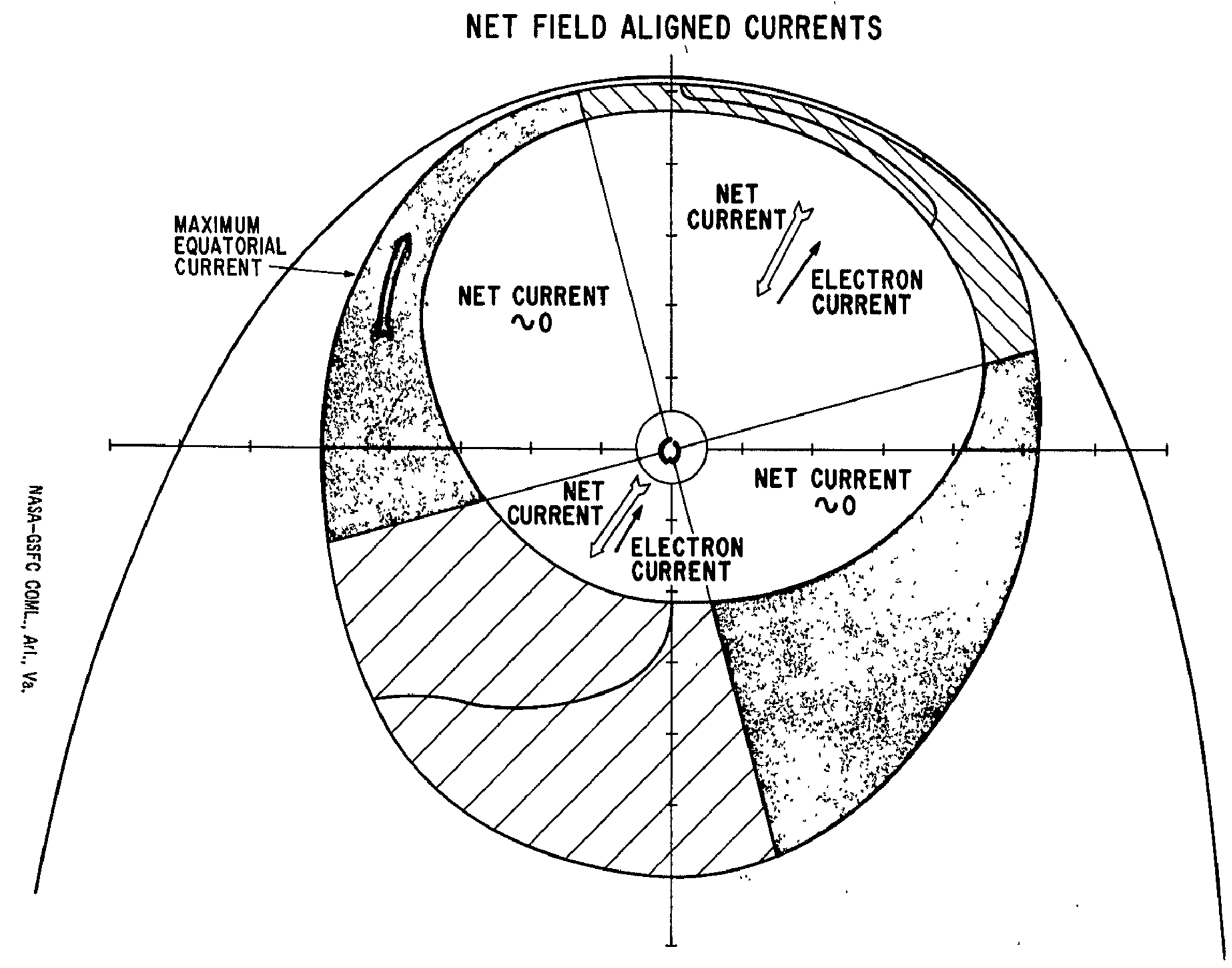

FIGURE 16 